\title{
Carbon Dioxide Mitigation through Controlled Photosynthesis
}

\author{
Final Report \\ Start Date: 09/01/1999 \\ End Date: 08/31/2000
}

DOE Award No.: DE-FG26-99FT40592

\author{
Ohio University \\ Dept. of Mechanical Engineering \\ Stocker Center \\ Athens, Ohio 45701-2979
}




\section{Table of Contents}

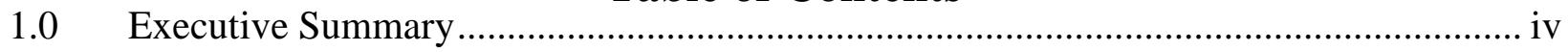

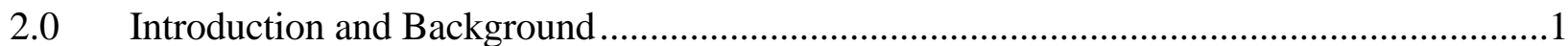

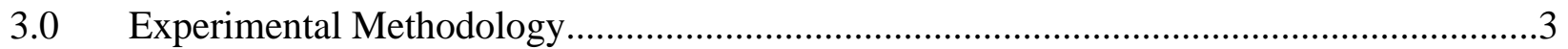

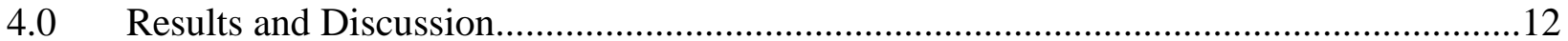

4.1 The Effect of Temperature on the Growth of Nostoc 86-3....................................12

4.2 The Effect of Light Intensity on the Growth of Nostoc 86-3 ................................. 17

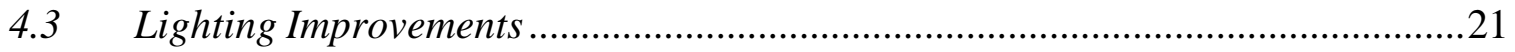

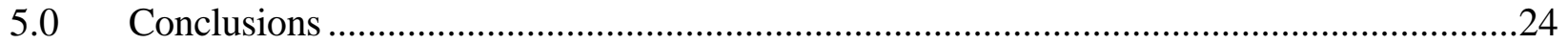

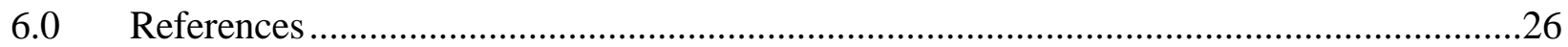




\section{List of Tables}

Table 1 - Difference in wet weight of screens for trial at $150^{\circ} \mathrm{F}$ (Experiment I) ...................12

Table 2 - Dry weight analysis for test samples (Experiment II) ........................................14

Table 3 - Difference in dry weight of screens for trial at $150^{\circ} \mathrm{F}$ (Experiment II) .................14

Table 4 - Dry weight analysis for test samples (Experiment III) .......................................15

Table 5 - Weight analysis of screens and filter (Experiment III) ........................................15

Table 6 - Dry weight analysis for test samples (Experiment IV) .........................................16

Table 7 - Weight analysis of screens and filter (Experiment IV) .......................................16

Table 8 - Light intensity measurement against distance inside the containment ...................16

Table 9 - Dry weight analysis for test samples (Experiment V) .......................................17

Table 10 - Weight analysis of screens and filter (Experiment V) .........................................17

Table 11 - Dry weight analysis for test samples (Experiment VI) ........................................18

Table 12 - Light intensity passing through the containment (Experiment VI) ......................18

Table 13 - Weight analysis of screens and filter (Experiment VI) .....................................19

Table 14 - Dry weight analysis for test samples (Experiment VII) ....................................19

Table 15 - Light intensity passing through the containment (Experiment VII) .....................20

Table 16 - Weight analysis of screens and filter (Experiment VII) .....................................20

\section{List of Figures}

Figure 1 - Photosynthetic conversion of $\mathrm{CO}_{2}$ to biomass and oxygen.................................

Figure 2 - View of the experimental setup ................................................................. 3

Figure 3 - Schematic of the Carbon Recycling Facility ..................................................

Figure 4 - Schematic flow diagram showing burner assembly ......................................6

Figure 5 - Schematic flow diagram showing growth solution recirculation system................7

Figure 6 - Dimensional features of screens ...............................................................

Figure 7- Original microalgae sample under 60x magnification .....................................13

Figure 8 - Treated microalgae samples from four screens under 60x magnification..............13

Figure 9 - Schematic diagram of light distribution measurement ....................................21

Figure 10 - Light on-off mode in lighting test I .....................................................22

Figure 11 - Light intensity distribution in lighting test I................................................22

Figure 12 - Light on-off mode in lighting test II...........................................................23

Figure 13 - Light intensity distribution in lighting test II...........................................23

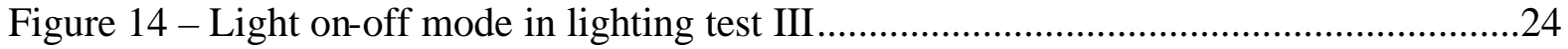

Figure 15 - Light intensity distribution in lighting test III ...........................................24 
Report Title: Carbon Dioxide Mitigation through Controlled Photosynthesis

Type of Report: Final Technical Report

Period Start: $\quad 09 / 01 / 1999$

Period End: $\quad$ 08/31/2000

Principal Authors: Dr. David J. Bayless

Dr. Morgan Vis

Dr. Gregory Kremer

Dr. Michael Prudich

Date Issued: $\quad 11 / 14 / 2000$

DOE Award No.: DE-FG26-99FT40592

Organization: Department of Mechanical Engineering

Ohio Coal Research Center

Department of Environmental and Plant Biology

248 Stocker Center

Athens, OH 45701-2979

bayless@ohio.edu

(740) 5930264 voice

(740) 5930476 fax

Disclaimer: This report was prepared as an account of work sponsored by an agency of the United States Government. Neither the United States Government nor any agency thereof, not any of their employees, makes any warranty, express or implied, or assumes any legal liability or responsibility for the accuracy, completeness, or usefulness of any information, apparatus, product, or process disclosed, or represents that its use would not infringe upon privately owned rights. Reference herein to any specific commercial product, process, or service by trade name, trademark, manufacturer, or otherwise does not necessarily constitute or imply its endorsement, recommendation, or favoring by the United States Government or any agency thereof. The views and opinions of authors expressed herein do not necessarily state or reflect those of the United States Government or any agency thereof. 


\subsection{Executive Summary}

This research was undertaken to meet the need for a robust portfolio of carbon management options to ensure continued use of coal in electrical power generation. In response to this need, the Ohio Coal Research Center at Ohio University developed a novel technique to control the emissions of $\mathrm{CO}_{2}$ from fossil-fired power plants by growing organisms capable of converting $\mathrm{CO}_{2}$ to complex sugars through the process of photosynthesis. Once harvested, the organisms could be used in the production of fertilizer, as a biomass fuel, or fermented to produce alcohols.

In this work, a mesophilic organism, Nostoc 86-3, was examined with respect to the use of thermophilic algae to recycle $\mathrm{CO}_{2}$ from scrubbed stack gases. The organisms were grown on stationary surfaces to facilitate algal stability and promote light distribution. The testing done throughout the year examined properties of $\mathrm{CO}_{2}$ concentration, temperature, light intensity, and light duration on process viability and the growth of the Nostoc.

The results indicate that the Nostoc species is suitable only in a temperature range below $125^{\circ} \mathrm{F}$, which may be practical given flue gas cooling. Further, results indicate that high lighting levels are not suitable for this organism, as bleaching occurs and growth rates are inhibited. Similarly, the organisms do not respond well to extended lighting durations, requiring a significant (greater than eight hour) dark cycle on a consistent basis. Other results indicate a relative insensitivity to $\mathrm{CO}_{2}$ levels between 7-12\% and $\mathrm{CO}$ levels as high as $800 \mathrm{ppm}$.

Other significant results alluded to previously, relate to the development of the overall process. Two processes developed during the year offer tremendous potential to enhance process viability. First, integration of solar collection and distribution technology from Oak Ridge laboratories could provide a significant space savings and enhanced use of solar energy. Second, the use of translating slug flow technology to cool the gas stream and enhance bicarbonate concentrations could both enhance organism growth rates and make the process one that could be applied at any fossil-fired power generation unit.

These results were au gmented by measurements of $\mathrm{CO}_{2}$ loss from the bioreactor test section. The corresponding mass balance was resolved to within $2 \%$, which is remarkable for the low level of $\mathrm{CO}_{2}$ actually absorbed by the cyanobacteria. The net result was approximately $10.2 \mathrm{~g}$ of $\mathrm{CO}_{2}$ absorbed of the original $2.97 \mathrm{~m}^{3}$ of circulating flue gas, (or about $19 \%$ of the original $\mathrm{CO}_{2}$ ). While this result in no way predicts the ability of the system to remove $\mathrm{CO}_{2}$ over the long term in a full-scale operating system, it appears to give credence to the workability of the system.

Other organisms are currently being cultured for experimentation, including a cyanidium and a thermophilic organism provided by the Department of Energy that has yet to be completely classified. Unfortunately, the large mass of photosynthetic organisms and culturing difficulties has prevented completion of testing with these organisms. However, the research described within has been the basis for a larger project starting October 2, 2000 for the Department of Energy (described by solicitation DE-PS26-99FT40613). These organisms will be examined as part of future work in reference to this new program. 


\subsection{Introduction and Background}

Biological carbon sequestration offers many advantages. Photosynthesis is the natural way to recycle carbon. Biomass developed from photosynthesis has numerous beneficial uses, the most attractive being a replacement fuel. Despite the large body of research in this area, virtually no work has been done to create a practical photosynthetic system for greenhouse gas control, one that could be used with both new and existing fossil units. For example, raceway cultivator use ignores land availability limitations at existing fossil generation plants. Few existing generation plants could find $100^{+}$acres of suitable land for siting a microbial pond, much less build and maintain one throughout a Midwestern winter. Additionally, how would the $\mathrm{CO}_{2}$ be introduced to the photosynthetic agents? Would expensively separated $\mathrm{CO}_{2}$ (not direct flue gas) be sparged because stack emissions requirements would prevent dispersion of flue gas at ground level? In addition, a practical biological sequestration would require improved lighting and photon delivery, a harvesting process to remove non-viable organisms and promote maximum carbon utilization, consideration of deleterious effects of the flue gas temperature and composition, and a plan for utilizing the biomass. The proposal presented in this document attempts to address these relevant problems in the design and analysis of a practical system for using photosynthesis in carbon sequestration.

Biological systems and in particular engineered photosynthesis systems are the best near-tointermediate term solution for reduced carbon emissions in the energy sector. First, in conversation with executives of a major regional electrical utility, the need for "other-thanocean" sequestration for fossil units located in the Ohio Valley and the Midwest became readily apparent. Second, the large capital and operating costs, complexity and energy required to transport $\mathrm{CO}_{2}$ make ocean sequestration prohibitive. Third, the product of natural sequestration, biomass, has numerous practical uses ranging from fertilizer to fuel. Fourth, it is clear that no one sequestration technique will solve the enormous problem of limiting carbon emissions from fossil generation units. Fifth, engineered photosynthesis systems could be made attractive to industry because they require no high-risk scientific breakthroughs. Photosynthesis is well understood, but there are no integrated practical processes for using it at fossil units for carbon sequestration. For coal to remain competitive and ensure future fuel diversification, a portfolio of viable and practical sequestration techniques will have to be developed and applied in an optimal manner based on each plant's circumstances. Photosynthetic systems must be a part of the portfolio.

The concept behind affordable engineered photosynthesis systems is simple. Even though $\mathrm{CO}_{2}$ is a fairly stable molecule, it is the basis for the formation of complex sugars (food) by green plants through photosynthesis. The relatively high content of $\mathrm{CO}_{2}$ in flue gas (approximately $14 \%$ compared to the $350 \mathrm{ppm}$ in ambient air) has been shown to significantly increase growth rates of certain species of cyanobacteria. Therefore, this application is ideal for contained system, engineered to use, specially selected (but currently existing), strains of cyanobacteria to maximize $\mathrm{CO}_{2}$ conversion to cyanobacterial biomass and thus not emitting the greenhouse gas to the atmosphere. In this case, the cyanobacteria biomass represents a natural sink for carbon sequestration. 


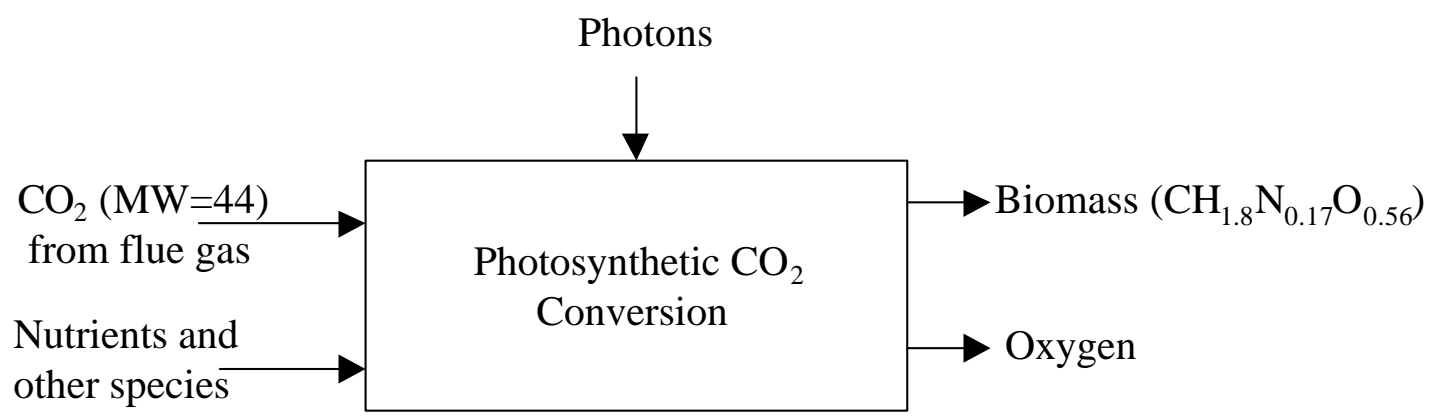

Figure 1. Photosynthetic conversion of $\mathrm{CO}_{2}$ to biomass and oxygen

Photosynthesis reduces carbon in the gas stream by converting it to biomass. As shown in Figure 1 , if the composition of "typical" cyanobacteria (normalized with respect to carbon) is $\mathrm{CH}_{1.8} \mathrm{~N}_{0.17} \mathrm{O}_{0.56}$, then one mole of $\mathrm{CO}_{2}$ is required for the growth of one mole of cyanobacteria. Based on the relative molar weights, the carbon from $1 \mathrm{~kg}$ of $\mathrm{CO}_{2}$ could produce increased cyanobacteria mass of $25 / 44 \mathrm{~kg}$, with $32 / 44 \mathrm{~kg}$ of $\mathrm{O}_{2}$ released in the process, assuming $\mathrm{O}_{2}$ is released in a one-to-one molar ratio with $\mathrm{CO}_{2}$. Therefore, a photosynthetic system provides critical oxygen renewal along with the recycling of carbon into potentially beneficial biomass.

Enhanced natural sinks are the most "economically competitive and environmentally safe" carbon sequestration options because they do not require pure $\mathrm{CO}_{2}$, and they do not incur the costs (and dangers) of separation, capture, and compression of $\mathrm{CO}_{2}$ gas. Among the options for enhanced natural sinks, the use of existing organisms in an optimal way in an engineered photosynthesis system is low risk, low cost, and benign to the environment. Additionally, this engineered photosynthesis system has the advantage of being at the source of the emissions to allow measurement and verification of the system effects, rather than being far removed from the emissions source, as is the case with forest-based and ocean-based natural sinks. Finally, the use of ocean-based sinks could present significant problems. It will be necessary to add large amounts of iron to the ocean to "use" the vast quantities of $\mathrm{CO}_{2}$ that might be added. As a result, there will be no control over resulting growth. "Weed" plankton, the most likely organisms to grow, will not provide sufficient nutrients for the food webs and there is a high probability of significant negative environmental impact. In the case of $\mathrm{CO}_{2}$ stored at the bottom of the ocean in "lakes," the adverse effects on the ocean-floor ecosystem cannot be predicted, but are likely to be considerable. The system we are proposing has little or no adverse environmental impact.

For low-concentration $\mathrm{CO}_{2}$ streams (such as the $14 \%$ mean $\mathrm{CO}_{2}$ concentration in waste flue gases from coal-fired power plants), the joint consideration of conversion of collected solar energy (using the Oak Ridge process) and natural carbon capture has the potential for significantly lowering carbon management costs. An engineered photosynthesis system can use (or recycle) waste $\mathrm{CO}_{2}$ to generate a store of reduced carbon in the form of biomass that could be used as a fuel, fertilizer, feedstock or sink for disposal. Further, engineered photosynthesis systems appear to fit into DOE's long-term plan to integrate biological processes into energyplexes to sequester carbon and produce energy (via biomass). Finally, engineered photosynthesis systems will likely benefit from current research into enhancing the process of 
photosynthesis, either genetically or via catalysts. This synergistic effect could lead to significant $\mathrm{CO}_{2}$ reductions not otherwise possible.

The process presented in this proposal would be suitable for application at existing and future fossil units. It also has several advantages compared to other natural sequestration techniques. For this project, optimization is based on design of a mechanical system to best utilize existing organisms rather than on optimizing the desirable features of an organism by genetic manipulation. Genetically engineered organisms are notoriously unstable, especially when forced to grow at the high rates expected in this application. The process also requires relatively small amounts of space $\left(1 / 25^{\text {th }}\right.$ of a raceway cultivator design) and most of the required energy is provided by passively collected sunlight. Because the organisms are grown on membrane substrates arranged much like plates in an electrostatic precipitator, there is little pressure drop. From a solar energy utilization standpoint, this proposal offers a unique and cost-effective alternative using a new hybrid system that leverages two decades of advancements and cost improvements in the solar, optical coating, and large-core optical fiber industries. This method far surpasses previous attempts at distributing sunlight to enhance cyanobacteria growth. Finally, this system could be used in virtually any power plant with the incorporation of translating slug flow technology to create favorable conditions for cyanobacteria growth, such as reduced temperatures and enhanced bicarbonate concentration.

\subsection{Experimental Methodology}

The experimental and test facilities are designed to simulate the flue gas emission from fossilfired power plants. Flue gases from fossil unit scrubber for $\mathrm{SO}_{\mathrm{x}}$ control contain $10-15 \% \mathrm{CO}_{2}$ and have a temperature around $150^{\circ} \mathrm{F}$. It is likely that thermophylic cyanobacteria, which tolerate high $\mathrm{CO}_{2}$ and elevated temperature, would be most suitable for reducing these $\mathrm{CO}_{2}$ emissions. For this reason microalgae species, Nostoc 86-3 from the Foundation of Microbial Analysis was selected for study. The effect of temperature, gas flow rate, $\mathrm{CO}_{2}$ concentration in the simulated flue gas and light intensity over the growth characteristics of microalgae species Nostoc 86-3 were examined at the test facility shown in Figure 2.

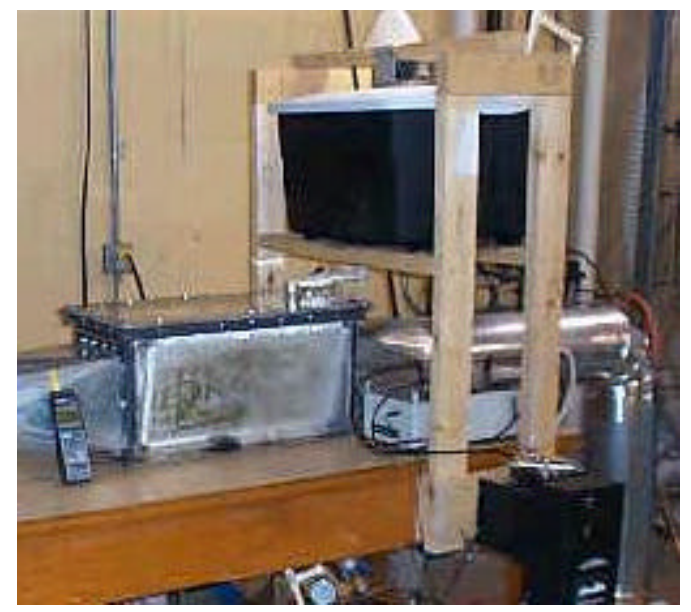

Figure 2. View of the experimental setup. 
The facility aims to develop a high-density, large-volume photosynthesizing microalgal culture system, to maximize the photosynthetic capacity. As with any diverse group of organisms, algae vary in requirements; with different media and handling techniques from culture to culture. Culturing media are the basis for establishing good quality algal culture, with selection of culturing media playing an important role in maintaining the culture for longer period of time. Nostoc 86-3 is cultivated axenically under myxotrophic conditions with a utilizable carbon source to supplement photosynthetic carbon dioxide assimilation.

The experiment setup can be viewed as the extension of earlier technology envisioned for open raceway cultivation ponds. The present setup incorporates passing simulated flue gas over the screens stacked vertically inside the containment on which microalgae species Nostoc 86-3 are grown. This assembly assists in reducing the pressure drop of flue gas as well as an increase in the effective area for efficient trapping and bio-conversion of $\mathrm{CO}_{2}$ in the flue gas. The experimental setup can be visualized as having following sub-systems; a flue gas recirculation system, a gas burner system, an algae grow solution recirculation system and an analysis system.

The flue gas recirculation system is designed to circulate hot flue gas through the algae culture in the containment facility. The recirculating fan circulates through the ductwork and containment the simulated flue gas (temperature $110^{\circ} \mathrm{F}$ and $7-12 \% \mathrm{CO}_{2}$ concentration) as found in a typical power plant that is scrubbed for $\mathrm{SO}_{\mathrm{x}}$. The simulated gas burned in the experimental setup is natural gas free from any solid impurities.

The containment facility is an open cubical box made of $1 / 4^{\prime \prime}$ thick Plexiglas, with the top cover made of $3 / 8$ " thick Plexiglas. Plexiglas was used because it can sustain high temperatures and it also provides transparency that allows visual monitoring of any changes occurring in the algae growth inside the containment. The containment facility is provided with a 1" PVC flange at the top edges, having twelve $3 / 8$ " holes. The top cover with matching holes is bolted to the flanged top with $1 / 4$ " bolts, nuts and washers. A $7 / 16$ " thick rubber gasket is applied between the top cover and flange.

The two faces of the box (12" wide x 113/4 high) are provided with two rectangular openings ( 9 " wide $x$ 8" high). These openings serve as the entry and exit of flue gas through the containment. The other openings provided in the box are, one at the bottom, (sized at $1 / 2$ ), for solution drain and two, (sized at $1 / 2$ ), on the top cover for the solution supply manifold and for insertion of a thermometer or thermocouple wire or light sensor. The openings are then sealed with thermal resistant glue and thermal sealing tape.

An inline centrifugal duct fan having variable speed control, maintains the circulation of flue gas through the setup. Galvanized ductwork, 8" in diameter and with a total length of approximately 20', provides passageway for the circulation of flue gas through the experimental facility. The ductwork is made of galvanized sheet metal rolled into cylindrical rolls 8 " in diameter x 2' long. Each duct piece is connected to another with rivets. The ductwork is connected to the circulation fan with steel hose clamps and terminated at the containment facility with two transition pieces at either end. 


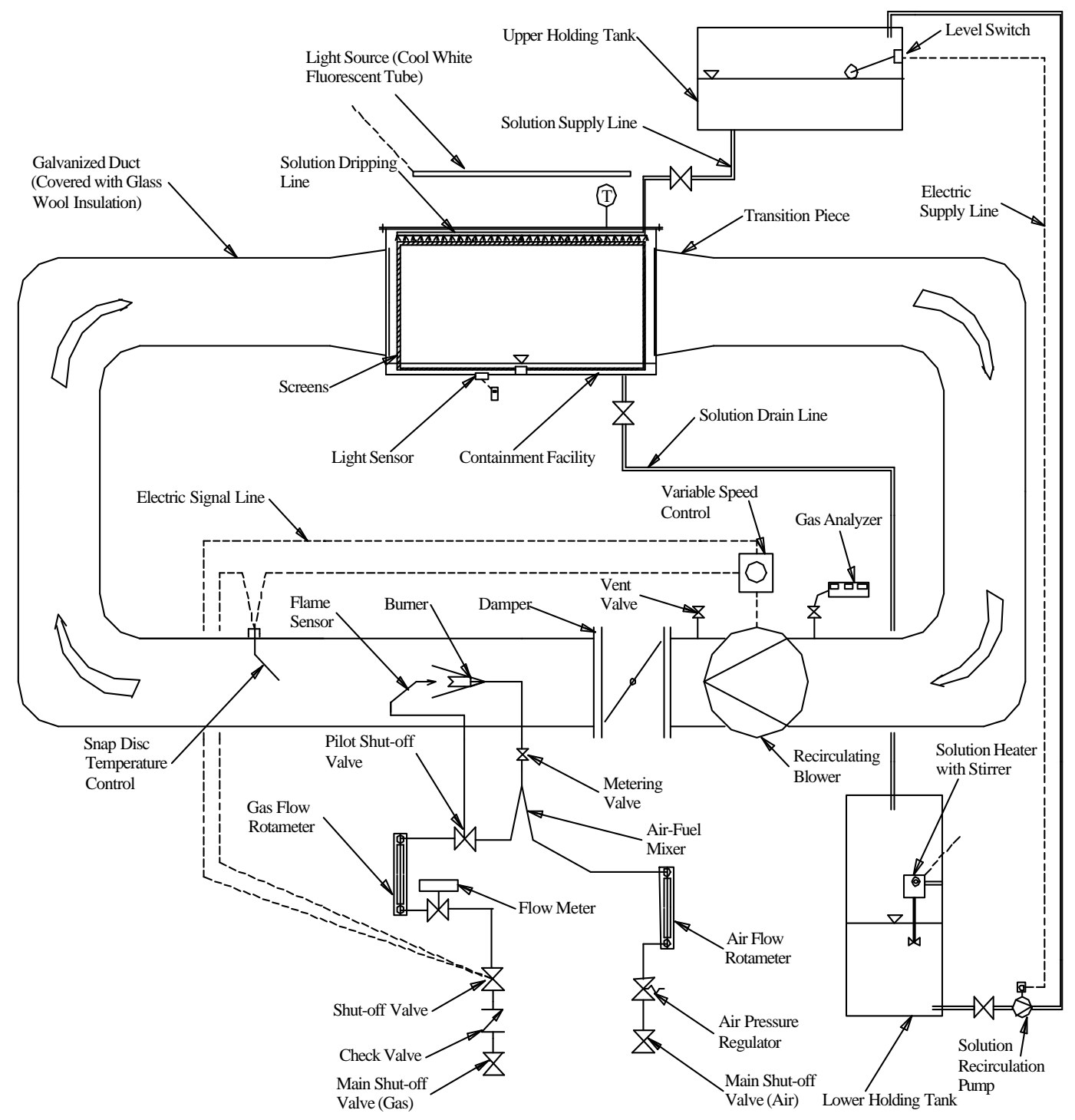

Figure 3. Schematic of the Carbon Recycling Facility

Transition pieces, rectangular (9" wide x 8 " high) to circular (8" diameter) and 12" long, made of galvanized sheet metal are connected to the containment facility with fourteen 1/4" nuts and bolts. Transition pieces are coupled to the ductwork with rivets. All the joints on the ductwork are thermally sealed with insulation tape. Two vent valves, sized 1/4" are fitted before and after the recirculation fan. One of the vent valves serves as a gas sample collector point for analyzer to assess the circulation gas for concentrations of $\mathrm{CO}_{2}, \mathrm{O}_{2}$ and $\mathrm{CO}$.

The gas burner system is primarily designed to maintain a suitable operating temperature range in the recirculating gas, while providing sufficient levels of $\mathrm{CO}_{2}$. The gas burner system is designed as a part of the gas recirculation system to preheat the circulating gas so as to simulate the actual power plant flue gas. The idea of burning premixed natural gas with air is to create a steady flame. Figure 4 is a schematic of the features of the burner assembly. 


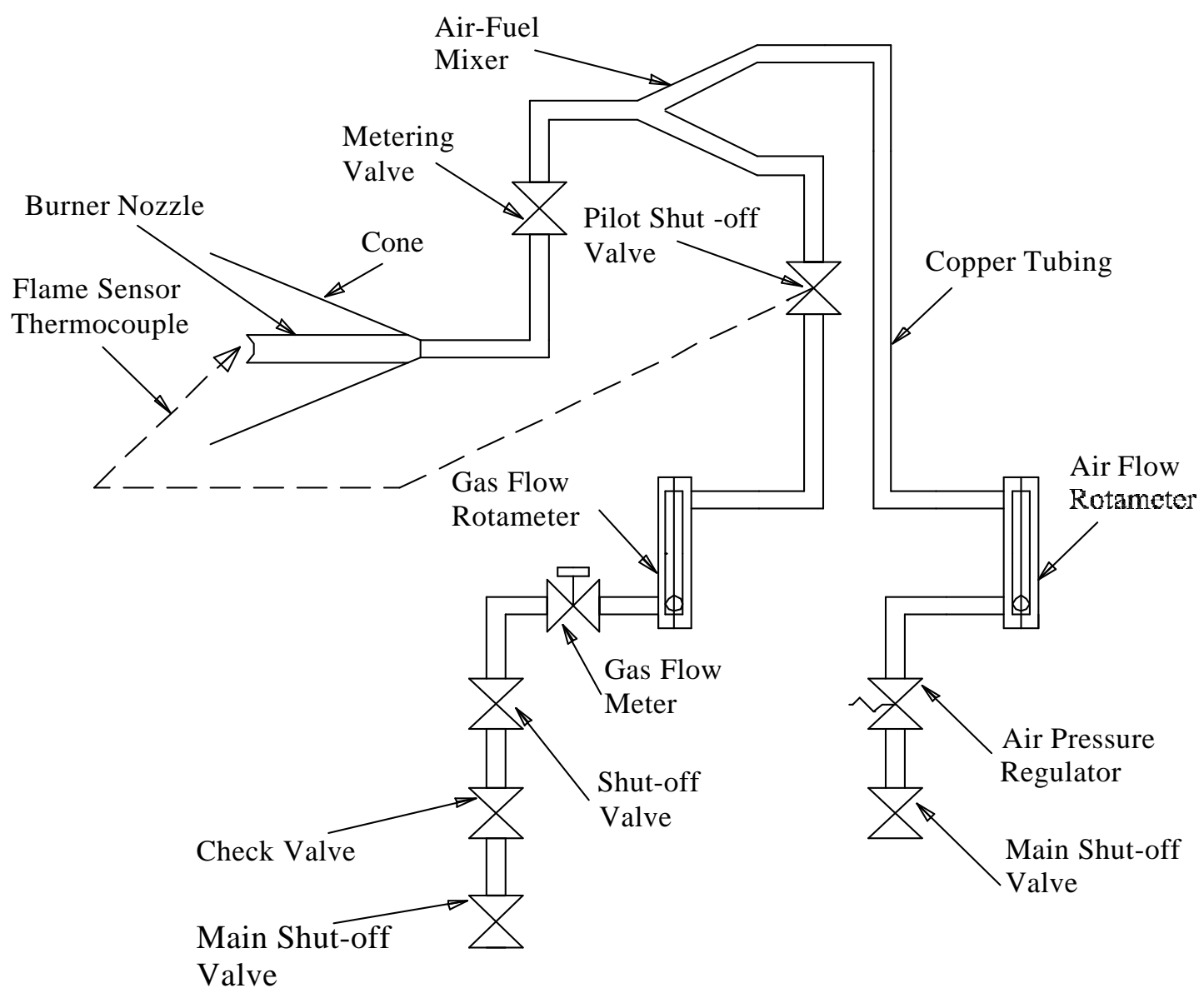

Figure 4. Schematic flow diagram showing burner assembly.

The burner assembly consists of a 2" long burner nozzle covered with a galvanized cone so as to protect the root of flame from the flow of circulating gas. The sub-assembly of burner nozzle, cone and flame sensor is mounted inside the ductwork and serves as a combustion chamber. This particular section of the burner assembly is accessible by opening the ductwork at the joint. The flame sensor is a safety device, which senses the flame/temperature at the burner nozzle and lets the pilot valve open, maintaining the flow of gas. When there's no flame the valve snaps shut and kills the supply of gas, preventing leakage of natural gas into the combustion chamber. Prior to entering the burner nozzle, natural gas is premixed with air in a Y-shaped air-fuel mixer. To sustain the flame in the flow field of gas, pressurized air is supplied to the burner. The premixed gas and air are metered through a metering valve after the mixer and then burned in the nozzle. The metering valve helps to provide fine control of the flame at the nozzle.

Another additional safety feature provided in the burner system is the snap disc temperature control. This temperature control is preset to $200^{\circ} \mathrm{F}$ so that if the temperature exceeds the preset value, the controller kicks off the recirculation fan and shuts off the gas supply valve so that no fuel is supplied, which, of course, prevents overheating of the system. Simultaneously the pilot shut-off valve kicks off due to no flame (because of lack of gas flow), adding additional safety to 
the setup. An air pressure regulator with filter is provided in the air supply line to regulate the pressure of air supplied for burning. In addition, check-valves in the gas supply line and main shut-off valves are provided to manually shut off the system when not running.

A recirculation system is designed to circulate the culturing media through the algae culture dispersed over screens while they are subjected to the high temperature flue gas in the containment. The basic idea is to keep the algae cultures moist inside the containment and provide nourishment for them to grow even at high temperatures. Figure 5 illustrates in a schematic representation the features of the recirculation system.

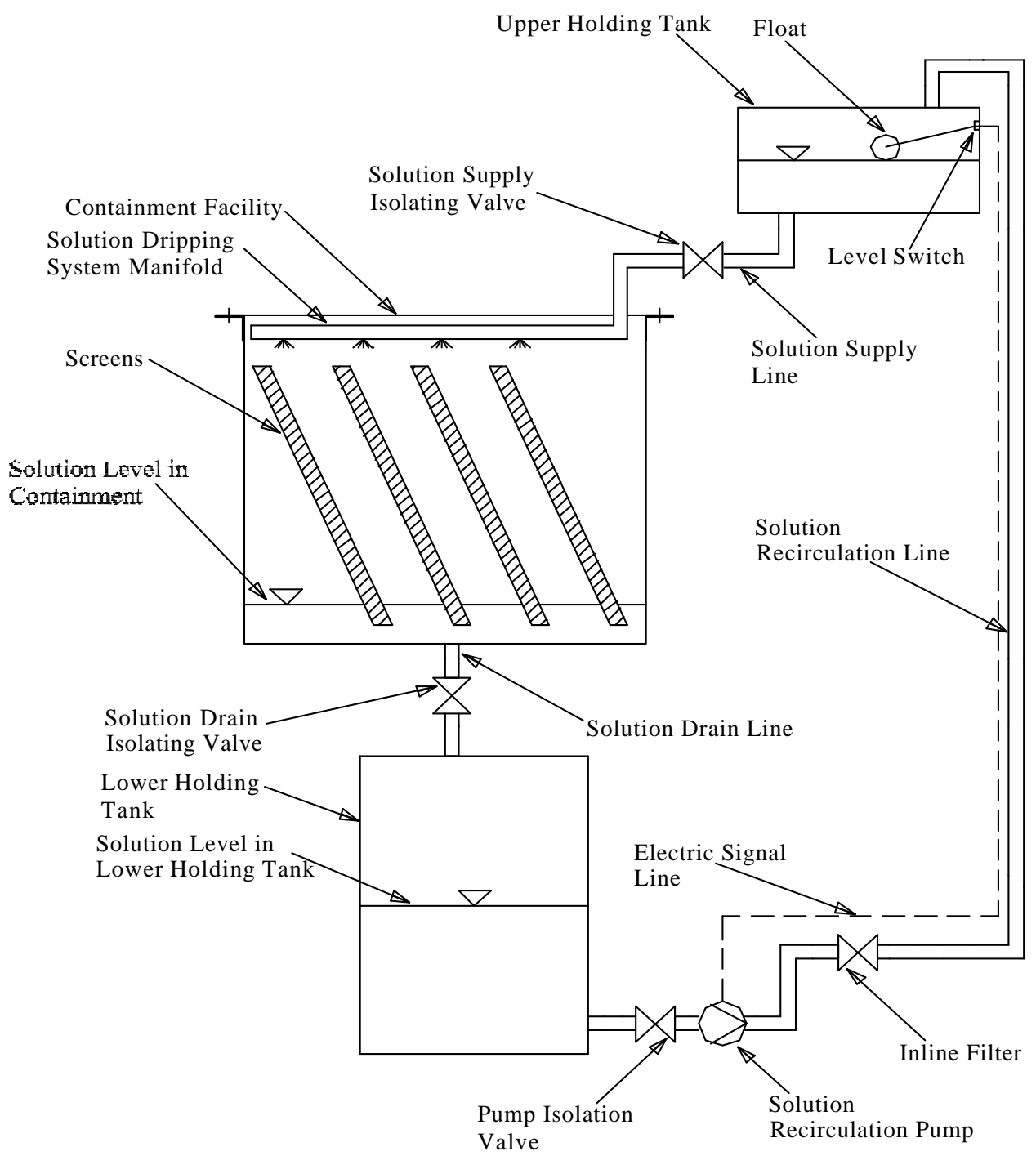

Figure 5. Schematic flow diagram showing growth solution recirculation system.

Four screens made of polyester fabric cloth fastened within the frame and loaded with algae culture are placed inside the containment at an angle of $65^{\circ}$. Screens are $21^{\prime \prime}$ long x $101 / 2$ wide with $1 / 2$ frame width. Figure 6 shows the dimensional features of the screens. 


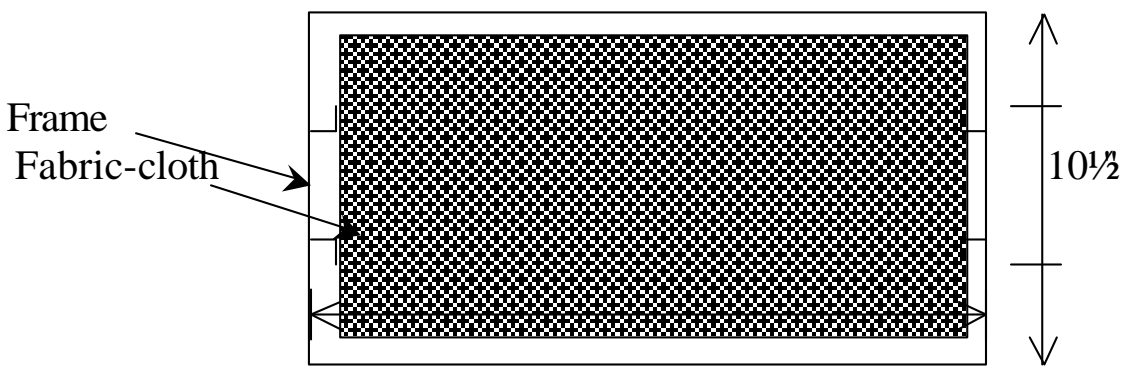

Figure 6. Dimensional features of screens.

Screens are supported inside the containment by a slotted fixture covering the width of the containment. The slotted fixture has four slots cut at an angle of $65^{\circ}$. The growth solution (medium I) is dripped through a solution dripping manifold over the screens from a plastic upper holding tank with an 18 gallon capacity. The manifold is a 1/2 PVC pipe system with the main supply line divided into four branches, 22" long for each screen. Each branch is provided with twenty $1 / 8$ " diameter holes to drip solution over the screens. Solution from the upper holding tank flows through the manifold under gravity and flow can be controlled with the isolating valve provided in the supply line.

Solution collected in the containment is drained back to the steel lower holding tank, with a capacity of 24.2 gallons. Both tanks are black so as to prevent any photosynthetic reaction in the solution due to external light. Algae solution from the lower holding tank is pumped back to the upper holding tank by a recirculation pump after passing through an inline $5 \mu \mathrm{m}$ rated filter to trap any algae passing through and to circulate a clear solution free of algae.

The upper holding tank is provided with a switch set to maintain the level of the solution in the tank so as to provide a continuous flow of solution over the screens. The float-type switch activates the recirculation pump on low level, and when the desired upper level is reached, shuts off the pump.

Analysis of the recirculating gas, growth solution and light intensity inside the containment is performed to quantify the $\mathrm{CO}_{2}$ absorption capacity of Nostoc 86-3 microalgae. The flue gas is analyzed for temperature, $\mathrm{O}_{2}, \mathrm{CO}_{2}$ and $\mathrm{CO}$ concentrations.

The temperature of the flue gas is measured by inserting the thermocouple wire into the flue gas stream in the containment. Flue gas is then analyzed for $\mathrm{CO}, \mathrm{CO}_{2}$ and $\mathrm{O}_{2}$ content using a Nova Analytical Systems Inc., model 375WP analyzer. Figure 3.4 shows the pictorial view of the gas analyzer. The analyzer utilizes a sensitive infrared detector for $\mathrm{CO}_{2}$ and disposable electrochemical sensors for $\mathrm{O}_{2}$ and $\mathrm{CO}$. A built in sample pump draws in the sample gas from the probe for analysis. The electrochemical $\mathrm{O}_{2}$ and $\mathrm{CO}$ sensors produce a small millivoltage output, which is directly proportional to the respective gas concentration. This output is amplified and displayed on the front panel meter. A solid-state infrared detector detects $\mathrm{CO}_{2}$, which is specific to $\mathrm{CO}_{2}$. Flue gas after detection is vented into the atmosphere. All three gases are simultaneously detected and displayed on LCD readout meters, one for each gas. The $\mathrm{pH}$ of recirculating 
solution is measured using Hanna Instruments made $\mathrm{pH}$ meter, model pHep. The range for the $\mathrm{pH}$ meter if from 0.0 to $14.0 \mathrm{pH}$ with resolution of $0.1 \mathrm{pH}$ and accuracy $\left(@ 20^{\circ} \mathrm{C}\right.$ ) of $\pm 0.1 \mathrm{pH}$.

Photosynthetically Active Radiation (PAR) is measured using a Licor LI-190SA quantum sensor. The quantum sensor measures PAR received on a plane surface. A silicone photodiode with an enhanced response in the visible wavelengths is used as the sensor.

Licor radiation sensors produce a current proportional to the radiation intensity. The current output of the sensor is measured over a milli-volt recorder by connecting an amplifier between sensor and recorder. The special purpose amplifier converts the micro-amp level current output of Licor light sensor to a corresponding signal voltage. LI-190SA sensor has a calibration constant of 6.67 or calibration multiplier of -149.93 . The calibration multiplier is the negative reciprocal of the calibration constant and is always a negative number because the shield of the coaxial cable is positive instead of negative, and is expressed in radiation units per microamp.

The setup is provided with a cool white light bank with an effective capacity of $612 \mathrm{~W}$. The light bank capacity is adjustable by adding or removing the $32 \mathrm{~W}$ tube lights from the fixtures. Total 9 fixtures are fixed and a pair of tube-lights can be mounted on each. The light bank resembles an enclosed trough and can be slid over the containment.

The LI-190SA is mounted at the base of the containment. The main idea is to measure the radiation from the artificial source of light (cool fluorescent light) passing through the screens and culture media. The output of the sensor from the millivolt adapter is boosted with an amplifier and measured over a millivolt recorder (multiplier).

An experimental investigation was carried out on Nostoc 86-3 microalgae species to determine temperature response, $\mathrm{CO}_{2}$ absorption and growth characteristics of the species under simulated flue gas conditions. For each experiment, the steps involved were:

1) preparing algae culture

2) sampling algae culture to determine mass of algae culture used for experimentation

3) preheating of containment facility and culturing solution

4) setup for gas analysis

5) measuring temperature and light sensor

6) trial of the experiment for a specific temperature and light intensity.

Microalgae species Nostoc 86-3 was isolated in pure culture from soil enrichment carried out under conditions of fixed nitrogen and selection of hormogonia induced by red light. The species were cultured in 20 gallons of culture medium I (described in Appendix A). The algae culture was illuminated by a $42 \mathrm{~W}$ cool-white fluorescent lamp at an intensity of $64 \mu \mathrm{mol}-\mathrm{s}^{-1} \mathrm{~m}^{-2}$ and bubbled with air and $\mathrm{CO}_{2}$ mixed together in the ratio of 19:1. The fluidization created by the bubbled $\mathrm{CO}_{2}$ helps in uniform defra gmentation of algae samples and $\mathrm{CO}_{2}$ transport via bulk flow diffusion.

The algae colonies so cultured are later transferred into 6-gallon plastic sampling containments, from where the algae samples are drawn out for experimentation. Each containment is provided 
with sample draw out isolation valve and a closed circuit heater to maintain the algae samples at $110^{\circ} \mathrm{F}$ and a $\mathrm{pH}$ level of 7.4 . The reason for preheating the algae samples at $110^{\circ} \mathrm{F}$, arises from the effort to prevent algae samples from thermal shock when they are transferred from the culturing containment at ambient temperature to test temperature in an experimental facility.

The algae samples in sampling containments are illuminated by a bank of $60 \mathrm{~W}$ cool-white fluorescent lamps at an intensity of $64 \mu \mathrm{mol}-\mathrm{s}^{-1} \mathrm{~m}^{-2}$.

Algae samples, after being cultured and preheated, are taken for the sampling process. At least five samples of algae culture, each $25 \mathrm{ml}$ by volume, are drawn out and filtered through paper filter cones. The paper filter cones are oven heated at $150^{\circ} \mathrm{F}$ for 6 hours to remove any moisture content from the filter. After filtering through the paper filters, the samples are again heated in the oven at $150^{\circ} \mathrm{F}$ for 10 hours. The difference in dry weight of each paper filter gives the amount of algae sample filtered. The sum of the differences in algae weight through filter elements gives an estimate of the mass of the cyanobacteria sample loaded over screens in the experimental facility. The total amount of sample loaded over 4 screens is calculated proportionately from the weight of filtered samples.

A specific amount of cyanobacteria culture is loaded over each screen, either by directly pouring the algae solution over the screens or by using a peristatlic pump to distribute evenly over the screens. The pouring or distributing rate is adjusted so that the organisms get enough time to attach to the screen fabric.

For each trial experiment, the containment facility and algae growth solution to be circulated through screens inside the containment are preheated for 12 hours to the temperature at which the trial experiment is intended to be run. The containment facility upper and lower holding tanks are cleaned off, and a new filter element is fitted to the inline filter. The filter cartridge is preheated at $150^{\circ} \mathrm{F}$ for 6 hours to remove any moisture content and weighed before fitting. A new set of screens is prepared and preheated in an oven at $150^{\circ} \mathrm{F}$ for 6 hours. The dry weight of screens is noted before inserting them into the experimental facility. The lower holding tank is filled with new algae growth solution that is pumped into the upper holding tank to the required level.

To start preheating, a set of screens is fitted over the fixture at an angle of $65^{\circ}$. The top cover is fitted and bolted over the experimental facility and solution is dripped over the screens from the upper holding tank. The rate of dripping is adjusted to maintain a level of $1 / 2^{-}-3 / 4 "$ inside the facility. The solution is allowed to circulate between the upper and lower holding tank through screens, recirculation pump and inline filter. The main shut off valves for air and gas are opened and air pressure is adjusted to 20 psi. The temperature rating of the snap disc temperature control is adjusted to the desired operating temperature. With flow control knobs for both the air and gas rotameters closed and metering valve half throttled, the flame sensing thermocouple for the burner is heated with an external propane torch through an opening in the duct work to open the pilot valve. Air and gas flows are then adjusted to get a sharp blue flame at the burner tip. Slowly the metering valve is fully opened and again the rotameter knobs are adjusted to get a sharp blue flame at the burner tip. At this time the flue gas recirculating blower is switched on. Flow control knobs of air and gas flow rotameters are again adjusted to obtain desired temperature for 
preheating.

Once the experimental facility is preheated to the desired experimental temperature and samples are being cultured at $110^{\circ} \mathrm{F}$, the top cover is opened and the required quantity of cyanobacteria is introduced in equal amount over each screen. While loading the algae samples over the screens, the circulation of hot gas is kept running. Once the samples are loaded over each screen, the screens are fitted back inside the containment. And after the screens are inserted in the experimental containment, the top cover is fitted back and bolted down over the containment. Growth solution dripping rate is adjusted so that a level of $1 / 2^{-} 3 / 4$ " is maintained in the bottom of the containment facility. The level of algae solution in the upper holding tank is maintained constant by the level switch and recirculation pump.

Once again the temperature measuring thermocouple wire is inserted into the containment facility to record the temperature. Obviously the temperature will fall when samples are loaded on the screens. Once again the flow control knobs of the rotameters are adjusted to reach the desired experimental temperature.

After the temperature is set, the accessories for the experiment, (light sensor, light bank and gas analyzer), are fitted. The output of the light sensor is noted and converted into $\mu \mathrm{mol}-\mathrm{s}^{-1} \mathrm{~m}^{-2}$. The measuring probe for the gas analyzer is inserted into the vent opening provided near the flue gas recirculation blower. The analyzer gives $\mathrm{O}_{2}, \mathrm{CO}_{2}$ and $\mathrm{CO}$ concentration readings in parts per million. Depending upon the set experimental conditions the readings are noted. The flow control knobs for the rotameters are adjusted again to arrive at the desired temperature.

During each 120 hour trial experiment for specific amounts of algae samples and fixed temperature, readings for temperature, air and gas flow rotameter values, light intensity, $\mathrm{O}_{2}, \mathrm{CO}_{2}$ and $\mathrm{CO}$ concentration are recorded. After the experiment is complete, the algae samples from each screen are compared to the original algae sample for visible changes in color and/or molecular characteristics (like cellular density and cellular structure). This analysis provides information about algae samples regarding their healthiness and growth characteristic features at high temperature as would be experienced in power plant flue gas. Also after the experiment is over the screens and inline filter element are dried and their weights are noted. Dry weight of screens and filter is noted. Calculation of weight differences when compared to the original mass of algae samples loaded into the system gives information on the growth of algae when exposed to a particular temperature. 


\subsection{Results and Discussion}

These experiments examined the effects of temperature, gas flow rate, and $\mathrm{CO}_{2}$ concentration in the simulated flue gas and light intensity on the growth characteristics of microalgae species Nostoc 86-3. Healthiness and growth of algae samples are determined by visible change in color of cyanobacteria samples, cellular structure and cellular density, and difference in sum of dry weight of screens and inline filter cartridge when compared to the amount of algae sample loaded.

\subsection{The Effect Of Temperature on the Growth of Nostoc 86-3}

Two sets of experiments attempted to study the ability of microalgae species to sustain a temperature of $150^{\circ} \mathrm{F}$. The first of these experiments was carried out for 150 hours with the experimental containment illuminated by a bank of $60 \mathrm{~W}$ cool-white fluorescent lights of $33 \mu \mathrm{mol}-\mathrm{s}^{-1} \mathrm{~m}^{-2}$ intensity measured over the top cover of the experimental containment. The simulated flue gas contained $3.4 \% \mathrm{CO}_{2}, 14.8 \% \mathrm{O}_{2}$, and $650 \mathrm{ppm} \mathrm{CO}$. Wet weights of the screens before and after firing are expressed in Table 1.

Table 1. Difference in wet weight of screens for trial at $150^{\circ} \mathrm{F}$ (Experiment I).

\begin{tabular}{|c|c|c|c|}
\hline$\underline{\text { Screen }}$ & Before trial & After trial & Difference \\
\hline$\# 1$ & $204.7 \mathrm{gm}$ & $168.1 \mathrm{gm}$ & $-36.6 \mathrm{gm}$ \\
\hline$\# 2$ & $224.6 \mathrm{gm}$ & $192.3 \mathrm{gm}$ & $-32.3 \mathrm{gm}$ \\
\hline \#3 & $240.7 \mathrm{gm}$ & $201.0 \mathrm{gm}$ & $-39.7 \mathrm{gm}$ \\
\hline \#4 & $242.3 \mathrm{gm}$ & $198.8 \mathrm{gm}$ & $-43.5 \mathrm{gm}$ \\
\hline
\end{tabular}

It was observed from this experiment that cyanobacteria samples were green colored for approximately 100 hours and then changed in color from dark green to brown. The density of cyanobacteria samples over the screens was drastically reduced, as is evident from the difference in the weight of the screens. It is important to note that no significant rate of growth was indicated from microscopic analysis. Microscopic images of the algae samples were not healthy enough as indicated by broken filaments, as presented in Figure 7.

Since the instantaneous carbon delivery rate did not appear to be limiting, other key parameters, (such as amount of cyanobacteria species loaded over the screens, period of dosing and the light intensity) that were considered for study. Results indicated that the cyanobacteria were unable to handle either the high temperature, the thermal shock resulting from the transition from room temperature, or both.

The next experiment was conducted at $150^{\circ} \mathrm{F}$ under the light intensity $33 \mu \mathrm{mol}-\mathrm{s}^{-1} \mathrm{~m}^{-2}$ measured at the top cover of experimental containment. However, for this experiment, the algae culture was preheated to $110^{\circ} \mathrm{F}$ in the sampling containment. Also, for this experiment, a more formal methodology was adopted for determining the mass of cyanobacteria loaded on the screens. As previously described, densities of algal solutions were measured out and used to calculate the mass loaded on the suspension screens. Table 2 gives the weight analysis of five $25 \mathrm{ml}$ samples drawn through paper filter elements for calculating of the weight of algae used in testing. 


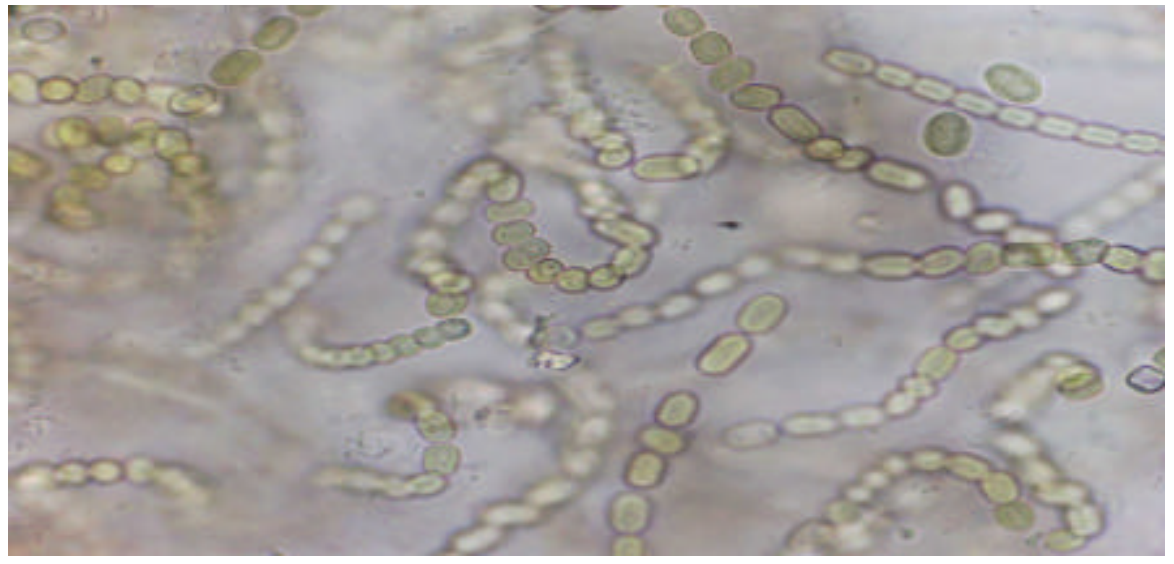

Figure 7. Original microalgae sample under 60x magnification.

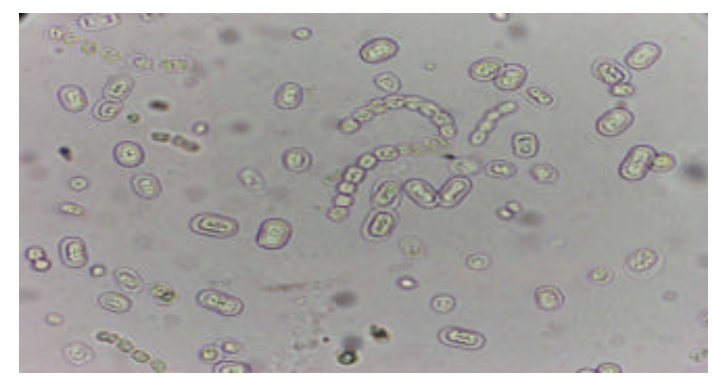

Screen \#1

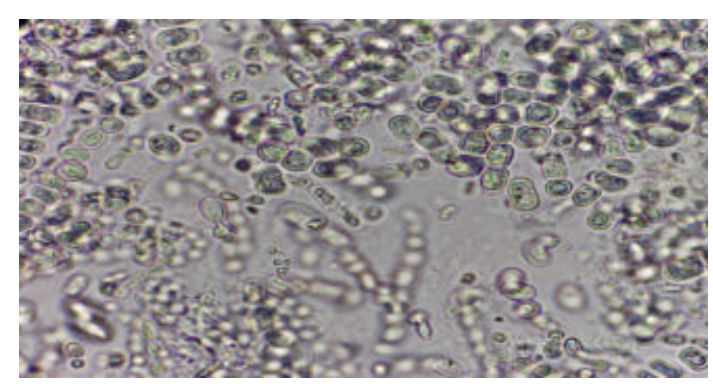

Screen \#3

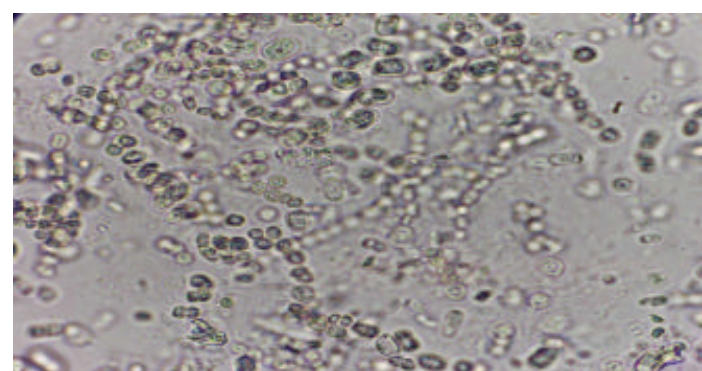

Screen \#2

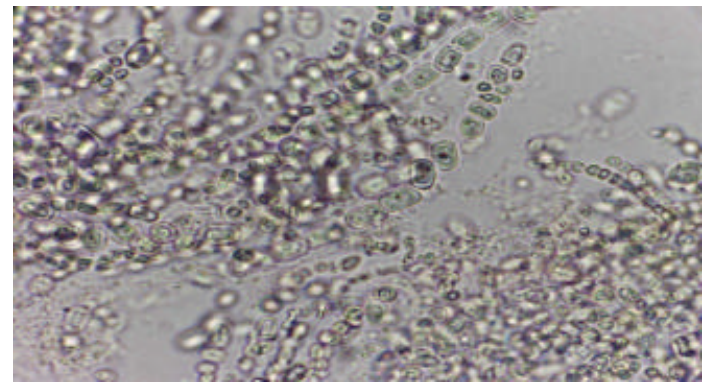

Screen \#4

Figure 8. Treated microalgae samples from four screens under 60x magnification. 
Table 2. Dry weight analysis of test samples (Experiment II).

\begin{tabular}{|c|c|c|c|c|}
\hline$\frac{\text { Filter }}{\text { number }}$ & Volume & $\frac{\text { Weight before }}{\text { filtering sample }}$ & $\frac{\text { Weight after }}{\text { filtering sample }}$ & Difference \\
\hline$\# 1$ & $25 \mathrm{ml}$ & $1.8036 \mathrm{gm}$ & $1.8219 \mathrm{gm}$ & $0.0183 \mathrm{gm}$ \\
\hline$\# 2$ & $25 \mathrm{ml}$ & $1.7522 \mathrm{gm}$ & $1.7744 \mathrm{gm}$ & $0.0222 \mathrm{gm}$ \\
\hline \#3 & $25 \mathrm{ml}$ & $1.8213 \mathrm{gm}$ & $1.8450 \mathrm{gm}$ & $0.0237 \mathrm{gm}$ \\
\hline \#4 & $25 \mathrm{ml}$ & $1.7275 \mathrm{gm}$ & $1.7502 \mathrm{gm}$ & $0.0227 \mathrm{gm}$ \\
\hline$\# 5$ & $25 \mathrm{ml}$ & $1.7050 \mathrm{gm}$ & $1.7283 \mathrm{gm}$ & $0.0233 \mathrm{gm}$ \\
\hline Total $=$ & $125 \mathrm{ml}$ & & & $0.1102 \mathrm{gm}$ \\
\hline
\end{tabular}

$1088 \mathrm{ml}$ of algal solution containing cyanobacteria was added to each screen, for a total of $4352 \mathrm{ml}$ of algae solution used in the test. The effective amount of algae species used in the experiment was calculated as:

$$
\frac{0.1102}{125} * 4352=3.837 \mathrm{gm}
$$

With $\mathrm{CO}_{2}$ and $\mathrm{O}_{2}$ concentration parameters constant from Experiment $\mathrm{I}$, the cyanobacteria species started showing change in color from green to brown after 90 hours with reduced effective algae density over the screens. Mcroscopic analysis of the samples revealed images similar those in experiment I. Table 3 presents the dry weights of screens before and after firing at $150^{\circ} \mathrm{F}$ for Experiment II. The screens were dried at $150^{\circ} \mathrm{F}$ for 6 hours each time. It was observed from the weight analysis of the screens that there was no effective algae growth over the screens.

Table 3. Difference in dry weight of screens for trial at $150^{\circ} \mathrm{F}$ (Experiment II).

\begin{tabular}{|c|c|}
\hline Screen & Before trial \\
\hline$\# 1$ & $151.1 \mathrm{gm}$ \\
\hline \#2 & $149.8 \mathrm{gm}$ \\
\hline \#3 & $150.5 \mathrm{gm}$ \\
\hline \#4 & $150.3 \mathrm{gm}$ \\
\hline
\end{tabular}

$\begin{array}{cc}\text { After trial } & \text { Difference } \\ 151.2 \mathrm{gm} & 0.1 \mathrm{gm} \\ 149.5 \mathrm{gm} & -0.3 \mathrm{gm} \\ 150.0 \mathrm{gm} & -0.5 \mathrm{gm} \\ 150.8 \mathrm{gm} & 0.5 \mathrm{gm}\end{array}$

It was concluded from Experiments I and II that Nostoc 86-3 is not able to handle high temperatures of the order of $150^{\circ} \mathrm{F}$ when exposed under illumination of $33 \mu \mathrm{mol}-\mathrm{s}^{-1} \mathrm{~m}^{-2}$. This leads to the next series of experiments at lower temperatures.

The next experiments were carried out at temperatures lower than $150^{\circ} \mathrm{F}$ with each set of experiments quantified for specific weight of algae sample used for testing. In addition to changing experimental parameters, the cyanobacteria samples were preheated in incubation containers to minimize thermal shock upon transfer to the bioreactor. Experiment III was carried out for 120 hours at $130^{\circ} \mathrm{F}$ under an illumination of $33 \mu \mathrm{mol}-\mathrm{s}^{-1} \mathrm{~m}^{-2}$ measured at the top cover of the experimental containment. The amount of algae loaded over each screen was $2000 \mathrm{ml}$ giving total loading of $8000 \mathrm{ml}$ in reactor. Table 4 gives the weight analysis of five numbers of $25 \mathrm{ml}$ samples drawn through paper filters for calculation of weight of algae used for testing. 
Table 4. Dry weight analysis for test samples (Experiment III).

\begin{tabular}{|c|c|c|c|c|}
\hline$\frac{\text { Filter }}{\text { number }}$ & Volume & $\begin{array}{l}\text { Weight before } \\
\text { filtering sample }\end{array}$ & $\frac{\text { Weight after }}{\text { filtering sample }}$ & Difference \\
\hline$\# 1$ & $25 \mathrm{ml}$ & $1.6941 \mathrm{gm}$ & $1.7052 \mathrm{gm}$ & $0.0111 \mathrm{gm}$ \\
\hline$\# 2$ & $25 \mathrm{ml}$ & $1.7275 \mathrm{gm}$ & $1.7398 \mathrm{gm}$ & $0.0123 \mathrm{gm}$ \\
\hline \#3 & $25 \mathrm{ml}$ & $1.8165 \mathrm{gm}$ & $1.8259 \mathrm{gm}$ & $0.0094 \mathrm{gm}$ \\
\hline \#4 & $25 \mathrm{ml}$ & $1.7423 \mathrm{gm}$ & $1.7514 \mathrm{gm}$ & $0.0091 \mathrm{gm}$ \\
\hline$\# 5$ & $25 \mathrm{ml}$ & $1.7347 \mathrm{gm}$ & $1.7438 \mathrm{gm}$ & $0.0092 \mathrm{gm}$ \\
\hline Total $=$ & $125 \mathrm{ml}$ & & & $0.0511 \mathrm{gm}$ \\
\hline
\end{tabular}

For $8000 \mathrm{ml}$, the effective amount of algae loaded was $3.270 \mathrm{gm}$. The simulated flue gas at $130^{\circ} \mathrm{F}$ contained $6.3 \% \mathrm{O}_{2}, 7.9 \% \mathrm{CO}_{2}$, and $1155 \mathrm{ppm} \mathrm{CO}$. Difference in dry weights of four screens and inline filter was calculated and the effective weight was compared with the weight of algae samples loaded. Table 5 tabulates the measured dry and differential weights.

Table 5. Weight analysis of screens and filter (Experiment III).

\begin{tabular}{|c|c|c|c|}
\hline Screen & Before trial & After trial & Difference \\
\hline$\# 1$ & $157.2 \mathrm{gm}$ & $\overline{157.7 \mathrm{gm}}$ & $0.5 \mathrm{gm}$ \\
\hline \#2 & $138.9 \mathrm{gm}$ & $139.1 \mathrm{gm}$ & $0.2 \mathrm{gm}$ \\
\hline \#3 & $143.8 \mathrm{gm}$ & $144.1 \mathrm{gm}$ & $0.3 \mathrm{gm}$ \\
\hline \#4 & $152.3 \mathrm{gm}$ & $152.5 \mathrm{gm}$ & $0.2 \mathrm{gm}$ \\
\hline Filter & $168.0 \mathrm{gm}$ & $168.2 \mathrm{gm}$ & $\begin{array}{c}0.2 \mathrm{gm} \\
\text { Total }=1.4 \mathrm{gm}\end{array}$ \\
\hline
\end{tabular}

It was again observed that the total differential weight of screens and filter was less than the loaded weight of algae samples over the screens before the experiment. It is evident that there was no significant growth in Nostoc 86-3. The microalgae species showed change in color from green to brown after 96 hours again with reduced effective algae density over the screens.

Because of poor growth performance at $130^{\circ} \mathrm{F}$, the next experiment (Experiment IV) was carried out at $120^{\circ} \mathrm{F}$ with an average PAR of of $33 \mu$ mol- $\mathrm{s}^{-1} \mathrm{~m}^{-2}$ measured at the top cover of the experimental containment. The amount of algae sample loaded over each screen was again $2000 \mathrm{ml}$ giving a total loading weight of $8000 \mathrm{ml}$ in the reactor. Table 6 gives the weight analysis of five $25 \mathrm{ml}$ samples drawn through paper filters for calculation of weight of algae used for testing. 
Table 6. Dry weight analysis for test samples ( Experiment IV).

\begin{tabular}{|c|c|c|c|c|}
\hline $\begin{array}{l}\text { Filter } \\
\text { number }\end{array}$ & Volume & $\frac{\text { Weight before }}{\text { filtering sample }}$ & $\frac{\text { Weight after }}{\text { filtering sample }}$ & Difference \\
\hline$\overline{\# 1}$ & $25 \mathrm{ml}$ & $1.7249 \mathrm{gm}$ & $1.7538 \mathrm{gm}$ & $0.0289 \mathrm{gm}$ \\
\hline$\# 2$ & $25 \mathrm{ml}$ & $1.6523 \mathrm{gm}$ & $1.6796 \mathrm{gm}$ & $0.0273 \mathrm{gm}$ \\
\hline \#3 & $25 \mathrm{ml}$ & $1.7137 \mathrm{gm}$ & $1.7422 \mathrm{gm}$ & $0.0285 \mathrm{gm}$ \\
\hline \#4 & $25 \mathrm{ml}$ & $1.7773 \mathrm{gm}$ & $1.8068 \mathrm{gm}$ & $0.0295 \mathrm{gm}$ \\
\hline$\# 5$ & $25 \mathrm{ml}$ & $1.6787 \mathrm{gm}$ & $1.7086 \mathrm{gm}$ & $0.0299 \mathrm{gm}$ \\
\hline Total $=$ & $125 \mathrm{ml}$ & & & $0.1441 \mathrm{gm}$ \\
\hline
\end{tabular}

The effective amount of algae loaded was $9.22 \mathrm{gm}$. The simulated flue gas composition at $120^{\circ} \mathrm{F}$ was identical to one for Experiment III. After the experiment was run for 120 hours, the growth screens and filter were removed and dried. Table 7 tabulates the measured dry and differential weights.

Table 7. Weight analysis of screens and filter (Experiment IV).

\begin{tabular}{|c|c|c|c|}
\hline Screen & Before trial & After trial & Difference \\
\hline$\# 1$ & $151.3 \mathrm{gm}$ & $154.6 \mathrm{gm}$ & $3.3 \mathrm{gm}$ \\
\hline \#2 & $151.1 \mathrm{gm}$ & $151.6 \mathrm{gm}$ & $0.3 \mathrm{gm}$ \\
\hline \#3 & $156.2 \mathrm{gm}$ & $156.4 \mathrm{gm}$ & $0.2 \mathrm{gm}$ \\
\hline \#4 & $154.9 \mathrm{gm}$ & $156.3 \mathrm{gm}$ & $1.4 \mathrm{gm}$ \\
\hline Filter & $154.3 \mathrm{gm}$ & $155.7 \mathrm{gm}$ & $\begin{array}{c}1.4 \mathrm{gm} \\
\text { Total }=6.6\end{array}$ \\
\hline
\end{tabular}

An analysis was carried out over the light intensity that was captured by Nostoc 86-3 over the screens. Table 8 presents the intensity level available inside the containment.

Table 8. Light intensity measurement against distance inside the containment. (Light source $=60$ watts cool white fluorescent lamps)

\begin{tabular}{|c|c|c|c|}
\hline Outside & Inside & \multicolumn{2}{|c|}{ Light intensity } \\
\hline containment & containment & $\underline{\mathbf{m V}}$ & $\mu \mathrm{mol}-\mathrm{s}^{-1} \mathrm{~m}^{-2}$ \\
\hline $15 "$ & & $8 \overline{9.2}$ & 33.43 \\
\hline & $16 "$ & 69.8 & 26.16 \\
\hline & $20 "$ & 51.8 & 19.41 \\
\hline & $24 "$ & 11.3 & 4.23 \\
\hline & base & 4.8 & 1.79 \\
\hline base & & 3.2 & 1.19 \\
\hline
\end{tabular}

It can be observed from Table 8 that the light intensity passing into the containment was reduced by $96 \%$ as compared to the intensity over the top cover of the containment. The test results infer that the differential weights of algae samples after the trial were less than the loaded weight and that the algae species showed a change in color from green to brown after 110 hours. However, microscopic analysis of the algae samples taken from the screens revealed notably different 
results. The samples were found to be healthy with cells still forming chains although the average cell size was $1 / 2$ of the original culture. Although not conclusive, Experiment IV seemed to indicate that $120^{\circ} \mathrm{F}$ was a more suitable temperature for growth of Nostoc 86-3, and that in order to promote a positive increase in biomass, clearly other parameters had to be adjusted.

\subsection{The Effect of Light Intensity on the Growth of Nostoc 86-3}

With the results from Experiment IV in mind, Experiment V was carried out at $120^{\circ} \mathrm{F}$ once again, but with a higher luminance of $55 \mu \mathrm{mol}-\mathrm{s}^{-1} \mathrm{~m}^{-2}$ measured at the base of the experimental containment, after the growth samples were loaded over the screens. The amount of cyanobacteria over each screen was now $3000 \mathrm{ml}$, for a total loading of $12000 \mathrm{ml}$ in reactor. Table 9 gives the weight analysis of the $25 \mathrm{ml}$ samples drawn through paper filters for calculation of cyanobacteria mass.

Table 9. Dry weight analysis for test samples (Experiment V).

\begin{tabular}{|c|c|c|c|c|}
\hline$\frac{\text { Filter }}{\text { number }}$ & Volume & $\frac{\text { Weight before }}{\text { filtering sample }}$ & $\frac{\text { Weight after }}{\text { filtering sample }}$ & Difference \\
\hline$\# 1$ & $25 \mathrm{ml}$ & $1.7858 \mathrm{gm}$ & $1.7916 \mathrm{gm}$ & $0.0058 \mathrm{gm}$ \\
\hline$\# 2$ & $25 \mathrm{ml}$ & $1.7568 \mathrm{gm}$ & $1.7623 \mathrm{gm}$ & $0.0055 \mathrm{gm}$ \\
\hline \#3 & $25 \mathrm{ml}$ & $1.6728 \mathrm{gm}$ & $1.6773 \mathrm{gm}$ & $0.0045 \mathrm{gm}$ \\
\hline \#4 & $25 \mathrm{ml}$ & $1.7447 \mathrm{gm}$ & $1.7502 \mathrm{gm}$ & $0.0055 \mathrm{gm}$ \\
\hline \#5 & $25 \mathrm{ml}$ & $1.8452 \mathrm{gm}$ & $1.8509 \mathrm{gm}$ & $0.0058 \mathrm{gm}$ \\
\hline Total $=$ & $125 \mathrm{ml}$ & & & $0.0271 \mathrm{gm}$ \\
\hline
\end{tabular}

The effective amount of cyanobacteria loaded was $2.602 \mathrm{gm}$. The simulated flue gas at $120^{\circ} \mathrm{F}$ contained $10.0 \% \mathrm{O}_{2}, 5.7 \% \mathrm{CO}_{2}$, and 380ppm CO. The difference in dry weight of the screens and inline filter was calculated and the effective weight was compared with the weight of samples loaded. Table 10 tabulates the measured dry and differential weights.

Table 10. Weight analysis of screens and filter for experiment V.

\begin{tabular}{lccc} 
Screen & Before trial & After trial & Difference \\
\cline { 3 - 4 }$\# 1$ & $149.4 \mathrm{gm}$ & $149.6 \mathrm{gm}$ & $0.2 \mathrm{gm}$ \\
$\# 2$ & $151.6 \mathrm{gm}$ & $150.7 \mathrm{gm}$ & $0.0 \mathrm{gm}$ \\
$\# 3$ & $152.4 \mathrm{gm}$ & $151.9 \mathrm{gm}$ & $0.0 \mathrm{gm}$ \\
$\# 4$ & $153.2 \mathrm{gm}$ & $153.7 \mathrm{gm}$ & $0.5 \mathrm{gm}$ \\
Filter & $183.0 \mathrm{gm}$ & $183.9 \mathrm{gm}$ & $0.9 \mathrm{gm}$ \\
& & &
\end{tabular}

Because the Nostoc 86-3 changed from green to brown within 80 hours, it can be inferred that the growth performance of algae species not only depends upon the temperature but also the light intensity. Cyanobacteria are adapted to lower light environments. With higher light levels, the cyanobacteria cannot harvest themselves. Thus, the experiment was stopped at 90 hours.

The next experiment was again performed at $120^{\circ} \mathrm{F}$ but under reduced light intensity with 
controlled parameters of $\mathrm{CO}_{2}$ concentration. Average PAR was found to be $18.25 \mu \mathrm{mol}-\mathrm{s}^{-1} \mathrm{~m}^{-2}$ measured at the base of experimental containment after the algae samples were loaded over the screens in the containment. Again the amount of algae sample loaded over each screen was $3000 \mathrm{ml}$ giving a total loading of $12000 \mathrm{ml}$ in reactor. Table 11 gives the weight analysis of $25 \mathrm{ml}$ samples drawn through paper filters for calculation of weight of algae used for testing. The effective amount of algae loaded was $8.112 \mathrm{gm}$. The simulated flue gas at $120^{\circ} \mathrm{F}$ contained $10.0 \% \mathrm{O}_{2}, 5.7 \% \mathrm{CO}_{2}$, and $700 \mathrm{ppm} \mathrm{CO}$.

Table 11. Dry weight analysis for test samples for Experiment VI.

\begin{tabular}{|c|c|c|c|c|}
\hline$\frac{\text { Filter }}{\text { Number }}$ & Volume & $\frac{\text { Weight before }}{\text { filtering sample }}$ & $\frac{\text { Weight after }}{\text { filtering sample }}$ & Difference \\
\hline$\# 1$ & $25 \mathrm{ml}$ & $1.7282 \mathrm{gm}$ & $1.7435 \mathrm{gm}$ & $0.0153 \mathrm{gm}$ \\
\hline$\# 2$ & $25 \mathrm{ml}$ & $1.6294 \mathrm{gm}$ & $1.6455 \mathrm{gm}$ & $0.0161 \mathrm{gm}$ \\
\hline \#3 & $25 \mathrm{ml}$ & $1.8189 \mathrm{gm}$ & $1.8368 \mathrm{gm}$ & $0.0179 \mathrm{gm}$ \\
\hline \#4 & $25 \mathrm{ml}$ & $1.7889 \mathrm{gm}$ & $1.8066 \mathrm{gm}$ & $0.0177 \mathrm{gm}$ \\
\hline$\# 5$ & $25 \mathrm{ml}$ & $1.7488 \mathrm{gm}$ & $1.7663 \mathrm{gm}$ & $0.0175 \mathrm{gm}$ \\
\hline Total $=$ & $125 \mathrm{ml}$ & & & $0.0845 \mathrm{gm}$ \\
\hline
\end{tabular}

The light intensity passing through the containment was measured (at the bottom of the reactor), as shown in Table 12.

Table 12. Light intensity passing through the containment for Experiment VI.

\begin{tabular}{lcc}
$\begin{array}{l}\text { Time } \\
\text { (hours) }\end{array}$ & \multicolumn{2}{c}{ Light intensity } \\
\hline 0 & $\frac{\mathbf{m V}}{48.7}$ & $\underline{\underline{\mathbf{m}} \mathbf{\mathbf { m }}-\mathbf{s}^{-1} \mathbf{m}^{-2}}$ \\
21 & 51.2 & 18.25 \\
45 & 57.6 & 19.19 \\
58 & 67.8 & 25.41 \\
70 & 79.2 & 29.68 \\
77 & 83.8 & 31.41 \\
83 & 88.1 & 33.02 \\
93 & 89.8 & 33.65 \\
97 & 91.6 & 34.33 \\
109 & 92.6 & 34.70 \\
118 & 93.6 & 35.08 \\
120 & 94.2 & 35.30
\end{tabular}

The difference in dry weight of four numbers of screens and inline filter was calculated out and effective weight was compared with the weight of algae samples loaded. Table 13 tabulates the measured dry and differential weights. 
Table 13. Weight analysis of screens and filter for Experiment VI.

\begin{tabular}{|c|c|c|c|}
\hline$\underline{\text { Screen }}$ & Before trial & After trial & Difference \\
\hline$\# 1$ & $149.1 \mathrm{gm}$ & $150.5 \mathrm{gm}$ & $1.4 \mathrm{gm}$ \\
\hline \#2 & $155.6 \mathrm{gm}$ & $157.3 \mathrm{gm}$ & $1.7 \mathrm{gm}$ \\
\hline \#3 & $149.7 \mathrm{gm}$ & $151.3 \mathrm{gm}$ & $1.6 \mathrm{gm}$ \\
\hline \#4 & $151.7 \mathrm{gm}$ & $151.4 \mathrm{gm}$ & $-0.3 \mathrm{gm}$ \\
\hline Filter & $189.1 \mathrm{gm}$ & $193.6 \mathrm{gm}$ & $\begin{array}{c}4.5 \mathrm{gm} \\
\text { Total }=8.9 \mathrm{gm}\end{array}$ \\
\hline
\end{tabular}

It was observed during the experiment that Nostoc 86-3 did not change color (remained green), but still with reduced density on the screens. In addition, it was observed that amount of light intensity passing through the containment showed a continuous rise with time. The observation also supports the decrease in microalgae density over the screens as more and more light passed through. However, the amount of cyanobacteria obtained after the trial was more than that initially loaded, indicating a positive growth.

The next experiment was conducted at $120^{\circ} \mathrm{F}$ under the illumination of $22.11 \mu \mathrm{mol}^{-\mathrm{s}^{-1} \mathrm{~m}^{-2}}$ measured at the base of the experimental containment after the algae samples were loaded. Again the amount of algae samples loaded over each screen was $3000 \mathrm{ml}$ giving a total loading of $12000 \mathrm{ml}$ in the reactor. Table 14 gives the weight analysis of $25 \mathrm{ml}$ samples drawn through paper filters for calculation of weight of algae for testing. The effective amount of algae loaded was $12.50 \mathrm{gm}$. The simulated flue gas at $120^{\circ} \mathrm{F}$ contained $9.5 \% \mathrm{O}_{2}, 6.0 \% \mathrm{CO}_{2}$, and $500 \mathrm{ppm} \mathrm{CO}$.

Table 14. Dry weight analysis for test samples (Experiment VII).

\begin{tabular}{|c|c|c|c|c|}
\hline$\frac{\text { Filter }}{\text { Number }}$ & Volume & $\frac{\text { Weight before }}{\text { filtering sample }}$ & $\frac{\text { Weight after }}{\text { filtering sample }}$ & Difference \\
\hline$\# 1$ & $25 \mathrm{ml}$ & $1.7666 \mathrm{gm}$ & $1.7921 \mathrm{gm}$ & $0.0255 \mathrm{gm}$ \\
\hline$\# 2$ & $25 \mathrm{ml}$ & $1.7011 \mathrm{gm}$ & $1.7266 \mathrm{gm}$ & $0.0255 \mathrm{gm}$ \\
\hline \#3 & $25 \mathrm{ml}$ & $1.7402 \mathrm{gm}$ & $1.7668 \mathrm{gm}$ & $0.0266 \mathrm{gm}$ \\
\hline \#4 & $25 \mathrm{ml}$ & $1.8402 \mathrm{gm}$ & $1.8677 \mathrm{gm}$ & $0.0275 \mathrm{gm}$ \\
\hline \#5 & $25 \mathrm{ml}$ & $1.6527 \mathrm{gm}$ & $1.6778 \mathrm{gm}$ & $0.0251 \mathrm{gm}$ \\
\hline Total $=$ & $125 \mathrm{ml}$ & & & $0.1302 \mathrm{gm}$ \\
\hline
\end{tabular}

For this experiment, the illumination was maintained under ON-OFF mode (12 hours cycle) to support the light and dark reaction of cyanobacterial photosynthesis. The light intensity passing through the containment was measured after every 12 hours (at the bottom of the reactor), as shown in Table 15. 
Table 15. Light intensity passing through the containment (Experiment VII).

\begin{tabular}{lcc}
$\frac{\text { Time }}{\text { (hours) }}$ & \multicolumn{2}{c}{ Light intensity } \\
$\frac{\mathbf{m V}}{0}$ & $\frac{\mathbf{u m o l}^{-1} \mathbf{m}^{-2}}{59.0}$ & 22.11 \\
12 & 74.6 & 27.96 \\
24 & 73.4 & 27.51 \\
36 & 76.4 & 28.64 \\
48 & 77.7 & 29.12 \\
60 & 77.5 & 29.05 \\
72 & 74.0 & 27.74 \\
84 & 80.4 & 30.14 \\
96 & 84.5 & 31.67 \\
108 & 88.6 & 33.21
\end{tabular}

After the experiment was run for 120 hours, the growth screens and filter were removed and dried. Table 16 shows the tabulations for the measured dry and differential weights.

Table 16. Weight analysis of screens and filter ( Experiment VII).

\begin{tabular}{|c|c|c|c|}
\hline Screen & Before tria & After trial & Difference \\
\hline$\# 1$ & $146.8 \mathrm{gm}$ & $151.1 \mathrm{gm}$ & $5.3 \mathrm{gm}$ \\
\hline$\# 2$ & $148.1 \mathrm{gm}$ & $151.5 \mathrm{gm}$ & $3.4 \mathrm{gm}$ \\
\hline \#3 & $150.1 \mathrm{gm}$ & $152.8 \mathrm{gm}$ & $2.7 \mathrm{gm}$ \\
\hline \#4 & $148.3 \mathrm{gm}$ & $151.1 \mathrm{gm}$ & $2.8 \mathrm{gm}$ \\
\hline Filter & $137.6 \mathrm{gm}$ & $145.9 \mathrm{gm}$ & $\begin{array}{c}8.3 \mathrm{gm} \\
\text { Total }=22.5 \mathrm{~g}\end{array}$ \\
\hline
\end{tabular}

It was observed that the light intensity passing through the containment showed a small rise at various intervals. It was also observed that the Nostoc 86-3 changed color to light brown. Cellular study testified that the species were of consistent size with the batch culture of algae and maintained the filamentous morphology of Nostoc. Based on visual observations, the species were maintaining healthy coloration and were not dying off. These results indicated that species Nostoc $86-3$ can tolerate $120^{\circ} \mathrm{F}$ as observed from the color of the samples after the experiment.

These results were augmented by measurements of $\mathrm{CO}_{2}$ loss from the bioreactor test section during this test. The corresponding mass balance was resolved to within $2 \%$, which is remarkable for the low level of $\mathrm{CO}_{2}$ actually absorbed by the cyanobacteria. The net result was approximately $10.2 \mathrm{~g}$ of $\mathrm{CO}_{2}$ absorbed of the original $2.97 \mathrm{~m}^{3}$ of circulating flue gas, (or about $19 \%$ of the original $\mathrm{CO}_{2}$ ). While this result in no way predicts the ability of the system to remove $\mathrm{CO}_{2}$ over the long term in a full-scale operating system, it appears to give credence to the workability of the system. 


\subsection{Lighting Improvements}

Because the algae are distributed on the surface of the membrane in the containment facility, the even distribution of light intensity on the membrane is also important to the growth of algae. The following experiments try to give us an idea of the light distribution on the membrane. The horizontal frame of the membrane is denoted as the $\mathrm{X}$-axis and the vertical frame as the Y-axis. Measurements began at the top of the Y-axis (top of membrane frame) and proceeded in oneinch increments across the $\mathrm{X}$-axis, providing 17 intensity measurements, with the initial position denoted as point $(0,0)$ and the last as point $(16,0)$. The sensor was then repositioned at point $(0,-1)$ and the measurements repeated again to point $(16,-1)$. This was continued until the last position was reached on the Y-axis. One full-grid intensity test takes approximately 2 hours to perform. The data points were entered into MatLab, and a mesh plot was rendered to visualize the lighting effects on the membrane.

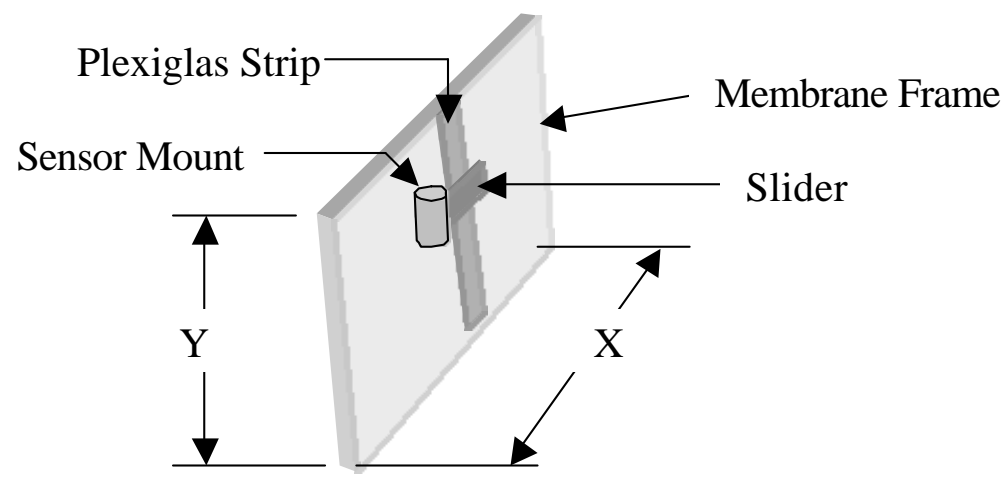

Figure 9. Schematic diagram of light distribution measurement.

Figure 10 denotes which lights were on and off during testing I. Figure 11 represents the light intensity for the first membrane in front of the reactor (the membrane closest to the incubator). Keep in mind that the screens are placed in the reactor at an angle. The top of the membrane is closer to the incubator than the bottom so we are measuring the intensity across the inside portion of the membrane. The X-axis and the Y-axis of the graph are in inches. The point $(0,0)$ represents the top left hand corner of the membrane. Visualize yourself on the back side of the system looking in at the membranes. The screen that is being measured is the one that is farthest away, nearest the incubator. Point $(0,0)$ is the top, left-hand corner of that screen. In the parentheses in the title of the graph is the light intensity unit that the LI-COR sensor measures in micromoles per s-meter squared and the intensity is represented by the color variations on the graph. The numbers on the color bar are the number of micromoles per s-meter squared at that shade of color.

Figure 11 shows an uneven axial and vertical intensity distribution. The main reason for the nonuniformity is the attenuation caused by the drip system running across the lid of the CRF. In addition, the selection lights that are illuminated during the testing also affect the distribution of light (see Figure 9). The minimum and maximum intensity measurements were 47.2 micromoles per s-meter squared (occurring at point $(0,0)$ ) and 139.9 micromoles per s-meter squared (occurring at point $(14,-1)$ ). This initial test was done to form a beginning basis. 

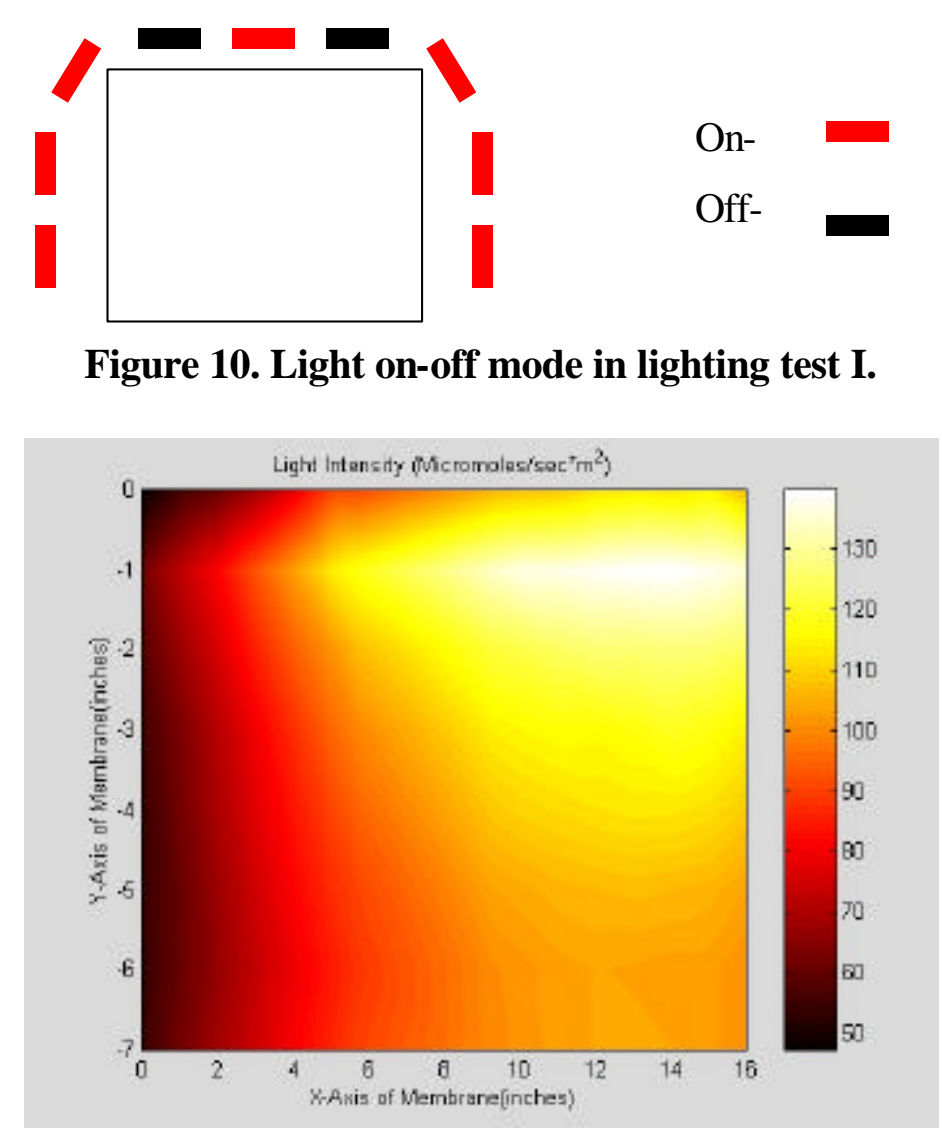

Figure 11. Light intensity distribution in lighting test $\mathbf{I}$.

Based on test I, changes were made to the lighting fixture. A round 30-Watt fluorescent light was inserted on the dark side of the CRF (end that contains the holding tank for the drip system). Because of the limited space between the CRF's lid, the lighting fixture and the holding tank, this seemed to be the most appropriate light to use without having to make moderate modifications to the lighting fixture. In addition, the lighting profile around the CRF was changed to see if more light would be delivered to the base of the membrane. (See Figure 12).

Figure 13 shows that the intensity is higher, distribution is moderately better, and it extends further down the membrane in test II. The left side of the membrane still remains shielded by the dripping system, and in particular, the feeding pipe for each of the four drippers. The minimum and maximum intensity measurements were 47.0 micromoles per s-meter squared (occurring at point $(0,-6))$ and 158.6 micromoles per s-meter squared (occurring at point $(14,-1)$ ). 


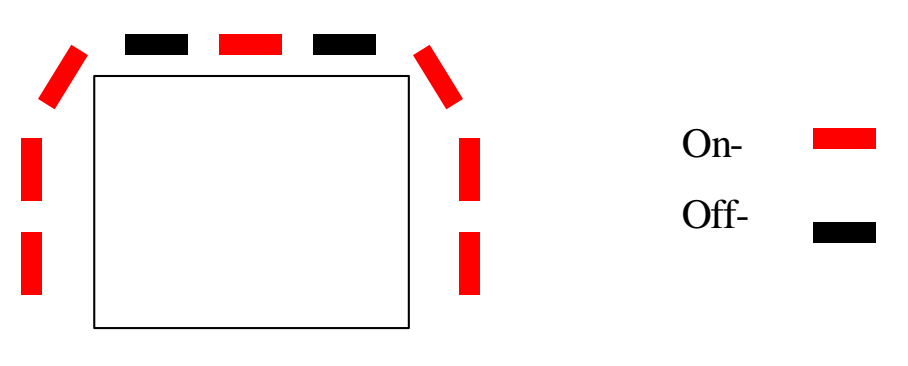

Figure 12. Light on-off mode in lighting test II.

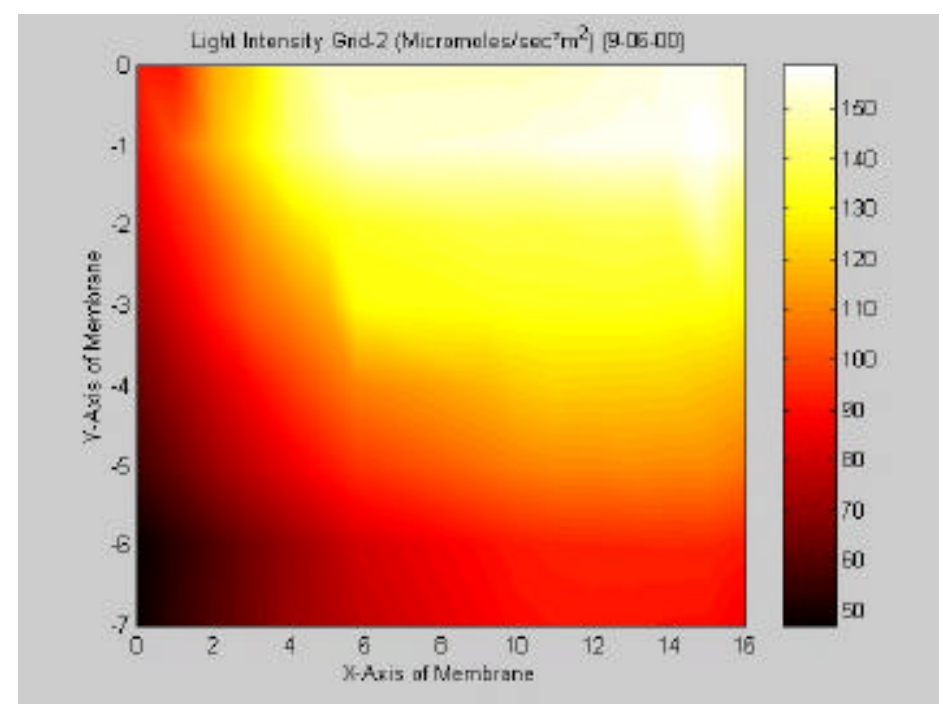

Figure 13. Light intensity distribution in lighting test II.

Test III was performed with the drip system removed. In addition, the sensor-mounting fixture was modified to allow an additional set of measurements to be taken. Be aware that Light Intensity Test III includes an additional set of points (points $(0,-8)$ through $(16,-8)$ ).

Figure 14 shows still more improvement on the intensity distribution. A large increase in intensity was observed across the entire membrane, with less darkening occurring toward the back of the CRF, but at higher values of intensity. In a preliminary discussion with Dr. Bayless, it was determined that the drip system might be modified to allow more light penetration. In addition, the screens could be shortened by approximately 2 inches. This would allow the membranes to be better centered in the CRF, enhancing the light distribution. The drip system modification would also alleviate the problem with droplets of growth media missing the membranes and being blown back into the ductwork. Growth media that is blown back into the ductwork causes tape degradation, and eventually leads to poor gas readings. Minimum and maximum values were 50.2 (point $(0,-8)$ ) and $247.8(14,0)$ micromole per second-meter squared. 


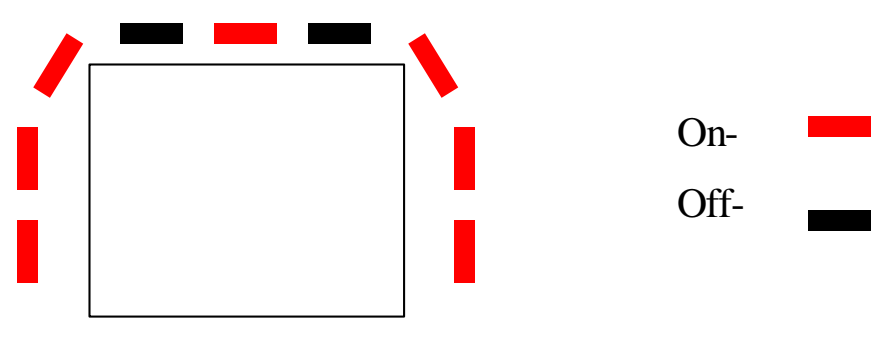

Figure 14. Light on-off mode in lighting test III.

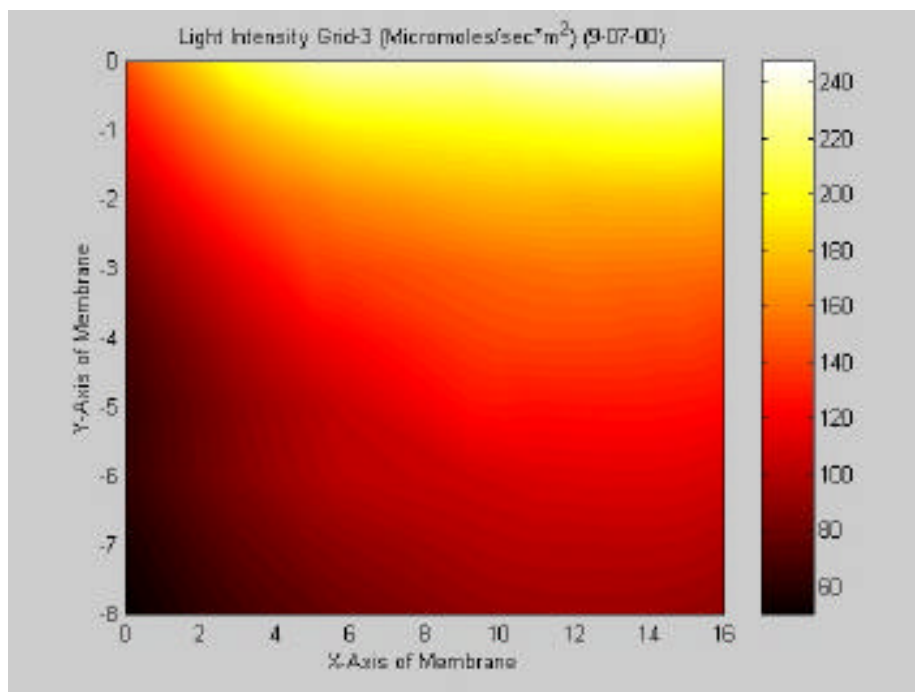

Figure 15. Light intensity distribution in lighting test III.

\subsection{Conclusions}

This work has produced results that indicate that a practical photosynthetic process, based on membrane biofilms, could sequester greenhouse gas emissions in biomass. Cyanobacteria were grown on membranes through photosynthesis using only carbon dioxide as the source of carbon. Experimental results indicate the mesophilic cyanobacteria (Nostoc) was able to grow at $125^{\circ} \mathrm{F}$, which is typical of flue gas from scrubbed (for $\mathrm{SO}_{2}$ removal) coal-fired power generation units. Further, the results indicate that low levels of lighting (40-60 $\mu$ mols $\left.\mathrm{m}^{-2} \mathrm{~s}^{-1}\right)$ are sufficient to grow these organisms at relatively high growth rates. However, other testing results indicate that these organisms are sensitive to temperatures above $130^{\circ} \mathrm{F}$, sensitive to light levels above 200 micromoles $\mathrm{m}^{-2} \mathrm{~s}^{-1}$ and generally unsuited for the conditions expected at a power generation unit that was not scrubbed for $\mathrm{SO}_{2}$ control. All totaled, these results indicate that the process is viable, even though the selected organism (which was picked for availability and not viability) was not.

As previously mentioned, the results of this study indicate that further work is needed before such a system could be considered for practical application. Specifically, issues of light delivery and distribution, enhancing growth rate through increased bicarbonate concentration, flue gas cooling, and harvesting to provide sustained growth, were addressed for long-term, full-scale 
functionality. While no repeatable results with respect to growth rates were performed for these issues, the investigation did reveal that potential solutions to these concerns exist.

Regarding the issue of lighting, Oak Ridge National Laboratory's work on hybrid fiber-optic lighting offers great promise for application to this work. Not only is light collected more efficiently by tracking the sun, photosynthetic photons can be distributed more efficiently by reducing overall photon concentrations to levels more suited to sustainable organism growth. Both bicarbonate concentration and flue gas cooling could be addressed by a technology developed at Ohio University known as a translating slug flow reactor. Harvesting was investigated using a number of mechanical processes, with simple water jet spray cleaning providing the least damage to the organisms and consistently removing 30-40\% of organisms from the membrane substrate.

Finally, it is important to remember that this is merely a work in progress. The effort will continue, addressing the concerns of scale - up to eventual application at an operational power generation unit. 


\subsection{References}

http://www.eia.doe.gov/

Allen M.M., and Stanier R.Y. "Selective isolation of blue-green algae on plates". J.Gen Microbiol. Vol.51 pp.203-209.

Aresta, M., Tommasi, I., "Carbon Dioxide Utilisation in the Chemical Industry," Energy Conversion and Management, Vol.38 (Supplemental Issue), 1997, pp. 373-378.

Bacastow R., and Dewey, R., "Effectiveness of $\mathrm{CO}_{2}$ Sequestration in the Post Industrial Ocean", Energy Conversion and Management, Vol. 37(6-8), 1996, pp. 1079-1086.

Benemann J., " $\mathrm{CO}_{2}$ Mitigation with Microalgae Systems", Energy Conversion and Management, Vol.38 (Supplemental Issue), 1997, pp. 475-479.

Brock, T.D., Thermophilic Microorganisms and Life at High Temperatures, Springer-Verlag, New York, 1978.

Castenholz R.W. "Culturing methods for cyanobacteria”. Methods Enzymol. Vol 167 (1988) pp. 68-93.

Cooksey, K.E., "Requirement of calcium in adhesion of a fouling diatom to glass", Appl.Env. Microbiol.Vol 41 (1981) pp. 1378-1382.

Cooksey K.E. and Cooksey B. "Adhesion of fouling diatoms to surfaces : Some biochemistry" In Algal Biofouling. Eds Evans L.V and Hoagland K.D.(1986), pp. 41-53.

Cooksey K.E. and Wigglesworth-Cooksey B., "Adhesion of bacteria and diatoms to surfaces in the sea : a review". Aquatic Microbial Ecol. Vol 9 (1995) pp.87-96.

Fairchild E.,and Sheridan R.P. "A physiological investigation of the hot spring diatom, Achnanthes exigua”,J. Phycol. Vol 10, (1974) pp. 1-4.

Ferris M.J. and Hirsch, C.F.'Method of isolation and purification of cyanobacteria".Appl.Env Microbiol. Vol 57(1991) pp. 1448-1452.

Fisher, A., "Economic Aspects of Algae as a Potential Fuel," Solar Energy Research, 1961, University of Wisconsin Press, pp. 185-189.

Geesey G.G, Wigglesworth-Cooksey, B. and Cooksey, K.E. "Influence of calcium and other cations on surface adhesion of bacteria and diatoms : A review." Biofouling (1999) in press.

Hanagata, N., Takeuchi, T., Fukuju, Y., Barnes, D., Karube, I., "Tolerance of Microalgae to High $\mathrm{CO}_{2}$ and High Temperature," Phytochemistry, Vol.31(10), 1992, pp. 3345-3348.

Hirata, S., Hayashitani, M., Taya, M., and Tone, S. "Carbon Dioxide Fixation in Batch Culture of Chlorella sp. Using a Photobioreactor with a Sunlight Collection Device,” Journal of Fermentation and Bioengineering, Vol.81, 1996, pp.470-472.

Kajiwara, S., Yamada, H., Ohkuni, N., and Ohtaguchi, K., "Design of the Bioreactor for Carbon Dioxide Fixation by Synechococcus PCC7942," Energy Conversion and Management, Vol.38 (Supplemental Issue), 1997, pp. 529-532.

Kaplan, A., Schwarz, R., Lieman-Hurwitz, J., and Reinhold, L., "Physiological and Molecular Aspects of the inorganic Carbon-Concentrating Mechanism in Cyanobacteria," Plant Physiology, Vol. 97, 1997, pp. 851-855.

Kondo J., T Inui, T., and Wasa, K. (Editors), Proceedings of the Second International Conference on Carbon Dioxide Removal, Oxford: Pergamon Press, 1995. 
Maeda, K., Owada, M., Kimura, N., Omata, K., Karube, I., " $\mathrm{CO}_{2}$ Fixation from the Flue Gas on Coal-Fired Thermal Power Plant by Microalage," Energy Conversion and Management, Vol.36(6-9), 1995, pp. 717-720.

Matsumoto, H., Shioji, N., Hamasaki, A., Ikuta, Y., Fukuda, Y., Sato, M., Endo, N., and Tsukamoto, T., "Carbon Dioxide Fixation by Microalgae Photosynthesis Using Actual Flue Gas Discharged from a Boiler," Applied Biochemistry and Biotechnology, Vol.51-52, 1995, pp. 681-692.

Miyairi, S. " $\mathrm{CO}_{2}$ Assimilation in a Thermophilic Cyanobacterium," Energy Conversion and Management, Vol.36(6-9), 1995, pp. 763-766.

Nagase, H., Eguchi, K., Yoshihara, K., Hirata, K., Miyamoto, K., "Improvement of Microalgal NOx Removal in Bubble Column and Airlift Reactors," Journal of Fermentation and Bioengineering, Vol. 86(4), 1998, pp.421-423.

Ohtaguchi, K., Kajiwara, S., Mustaqim, D., Takahashi, N., "Cyanobacterial Bioconversion of Carbon Dioxide for Fuel Productions," Energy Conversion and Management, Vol.38 (Supplemental Issue), 1997, pp. 523-528.

Rippka R. "Isolation and purification of cyanobacteria". Methods Enzymol.Vol. 167 (1988) pp. 3-27.

Vaara, T., Vaara,M., and Niemela, S. “Two improved methods for obtaining axenic cultures of cyanobacteria”. Appl. Env Microbiol. Vol.38 pp. 1011-1014.

Wigglesworth-Cooksey, B.van der Mei, H., Busscher H.J. and Cooksey K.E. "The influence of surface chemistry on the control of cellular behavior: Studies with a marine diatom. Colloids Surfaces : Biosurfaces (1999) Vol 15 pp. 71-79.

Yoshihara, K., Nagase, H., Eguchi, K., Hirata, K., Miyamoto, K., "Biological Elimination of Nitric Oxide and Carbon Dioxide from Flue Gas by Marine Microalga NOA-113 Cultivated in a Long Tubular Photobioreactor," Journal of Fermentation and Bioengineering, Vol. 82(4), 1996, pp.351-354. 